
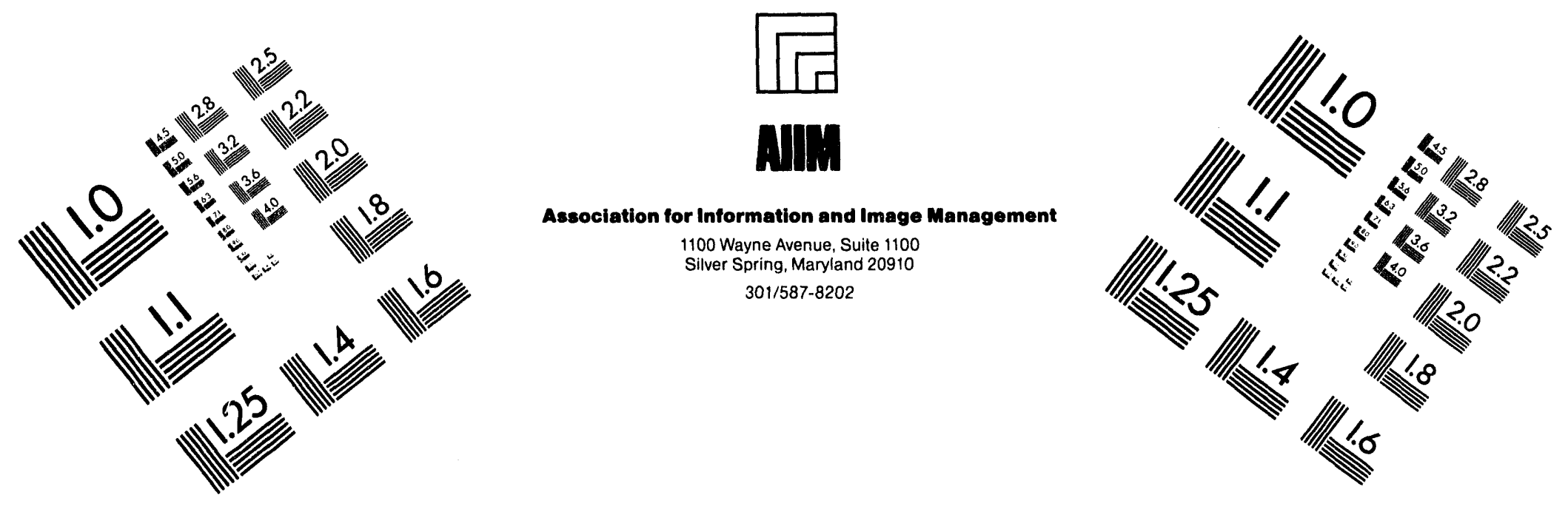

\title{
Centimeter
}

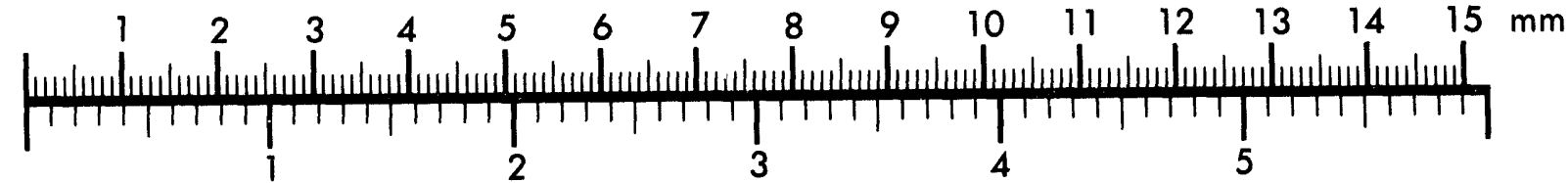
Inches
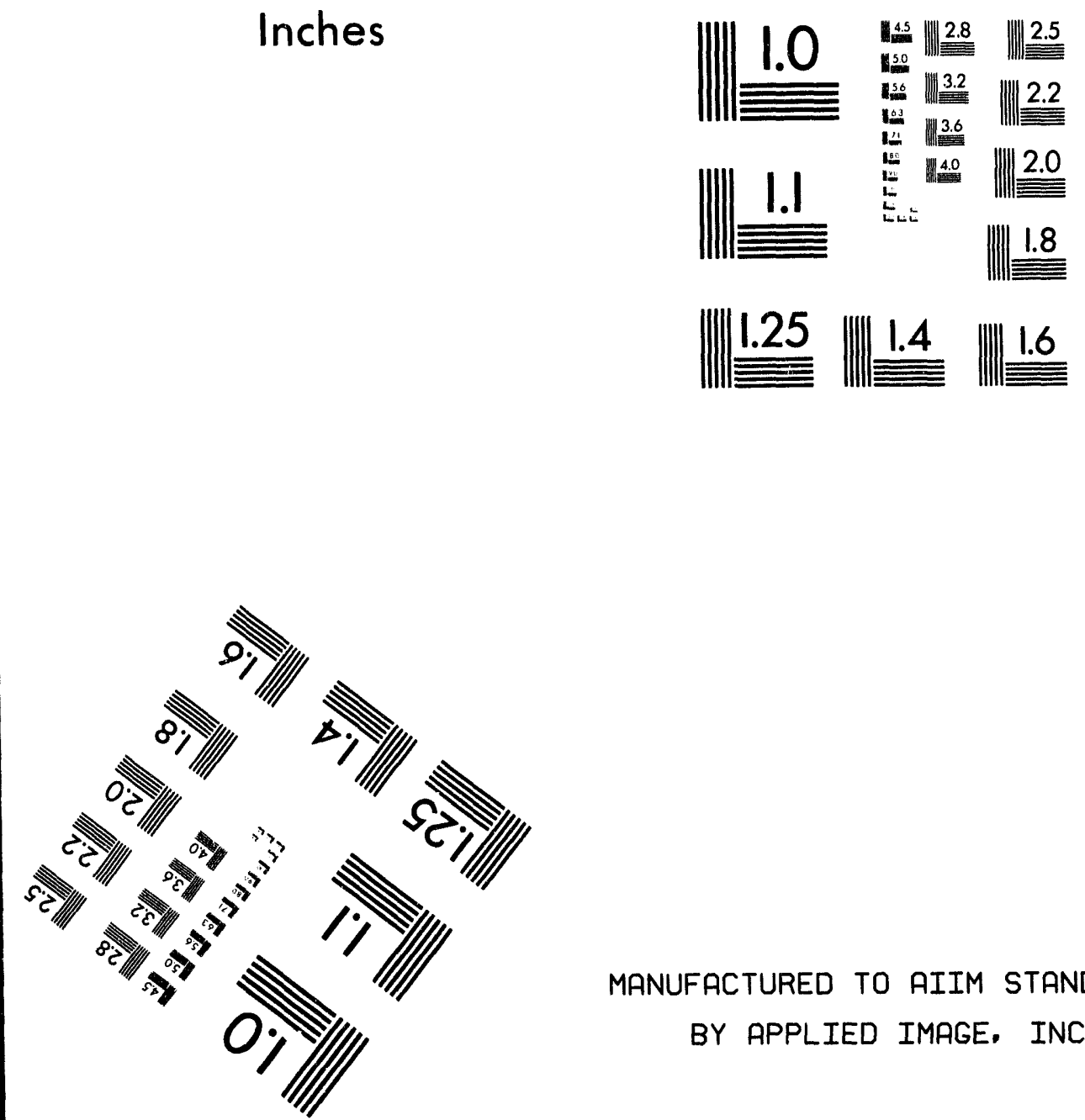

MANUFACTURED TO AIIM STANDARDS BY APPLIED IMAGE. INC.

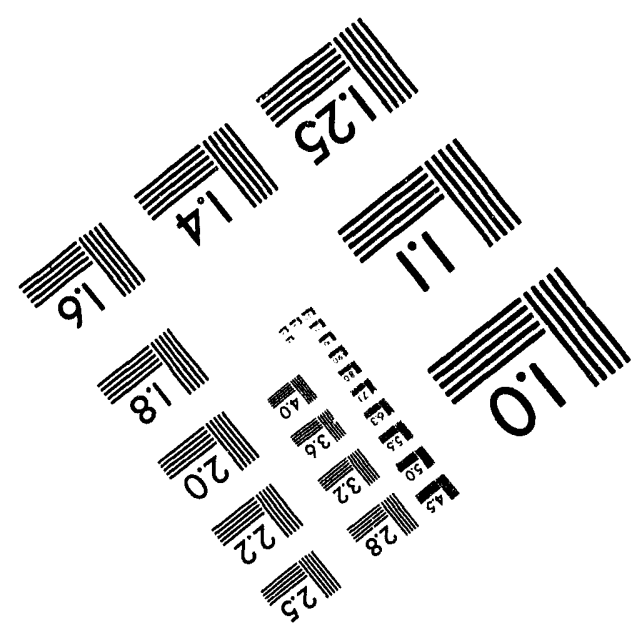



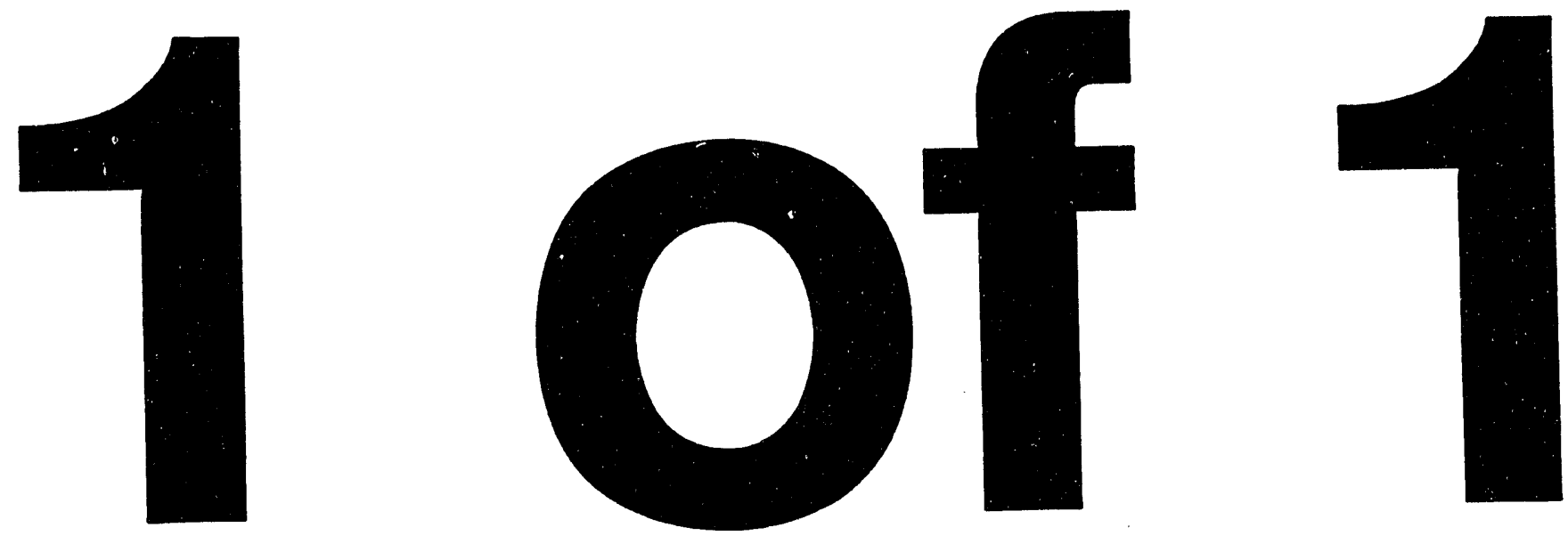


\section{DIVERTOR HEAT AND PARTICLE CONTROL EXPERIMENTS ON THE DIII-D TOKAMAK}

GA-A21706

by

M.A. MAHDAVI, S.L. ALLEN, ${ }^{*}$ D.R. BAKER, B. BASTASZ, ${ }^{\dagger}$ N.H. BROOKS, D. BUCHENAUER, ${ }^{\dagger}$ R.B. CAMPBELL, ${ }^{\dagger} J . W$. CUTHBERTSON, ${ }^{\dagger}$ T.E. EVANS, M.E. FENSTERMACHER, ${ }^{*}$ D.F. FINKENTHALL, $\ddagger$ J. FOOTE, ${ }^{*}$ D.N. HILL, ${ }^{*}$ D.L. HILLIS, $\sharp$

F.L. HINTON, J. HOGAN, A.W. HOWALD, AW. HYATT, G.L. JACKSON, R. JONG, ${ }^{*}$ S. KONOSHIMA, C. LASNIER, ${ }^{*}$ A.W. LEONARD, S.I. LIPPMANN, R. MAINGI, \# M.M. MENON, \# P.K. MIODUSZEWSKI, R.A. MOYER, ${ }^{\natural}$ H. OGAWA, ${ }^{b}$ T.W. PETRIE, G.D. PORTER, ${ }^{*}$ M.E. RENSINK, ${ }^{*}$ T.D. ROGNLIEN, ${ }^{*}$ M.J. SCHAFFER, K.M. SCHAUBEL, D.L. SEVIER, J.P. SMITH, G.M. STAEBLER, G.T. SAGER, R.D. STAMBAUGH, D.M. THOMAS, M.R. WADE, $\sharp$ J.G. WATKINS, ${ }^{\dagger}$ F. WESCHENFELDER, $₫$ W.P. WEST, D.G. WHYTE, $\triangle$ J. WINTER, $\$$ C.P.C. WONG, and R.D. WOOD*

This is a preprint of a paper to be presented at the Eleventh International Conference on Plasma Surface Interactions in Controlled Fusion Devices, May 23-27, 1994, Ibaraki-ken, Japan, and to be printed in the PROCEEDINGS.

Work supported by

U.S. Department of Energy

Contract Nos. DE-AC03-89F.R51114, W-7405-ENG-48,

DE-AC05-840R21400, DE-AC03-76DP00789, and Grant No. DE-FG03-89ER51121

* Lawrence Livermore National Laboratory.

† Sandia National Laboratories.

$\ddagger$ University of California at Berkeley.

"Oak Ridge National Laboratory, Oak Ridge, Tennessee.

b Japan Atomic Energy Research Agency.

I University of California at Los Angeles.

$\S$ Forschungzentrum (Association Euratom/KFA).

$\triangle$ CCFM.

GENERAL ATOMICS PROJECT 3466

MAY 1994 


\section{DISCLAIMER}

This report was prepared as an account of work sponsored by an agency of the United States Government. Neither the United States Government nor any agency thereof, nor any of their employees, makes any warranty, express or implied, or assumes any legal liability or responsibility for the accuracy, completeness, or usefulness of any information, apparatus, product, or process disclosed, or represents that its use would not infringe privately owned rights. Reference herein to any specific commercial product, process, or service by trade name, trademark, manufacturer, or otherwise, does not necessarily constitute or imply its endorsement, recommendation, or favoring by the United States Government or any agency thereof. The views and opinions of authors expressed herein do not necessarily state or reflect those of the United States Government or any agency thereof. 
In this paper we present a summary of recent DIII-D divertor physics activity and plans for future divertor upgrades. During the past year, DIII-D experimental effort was focused on areas of active heat and particle control and divertor target erosion studies. Using the DIII-D Advanced Divertor system we have succeeded for the first time to control the plasma density and demonstrate helium exhaust in $\mathrm{H}$-mode plasmas. Divertor heat flux control by means of $\mathrm{D}_{2}$ gas puffing and impurity injection were studied separately and in both cases up to a factor of five reduction of the divertor peak heat flux was observed. Using the DiMES sample transfer system we have obtained erosion data on various material samples in well diagnosed plasmas and compared the results with predictions of numerical models. 


\section{CONTENTS}

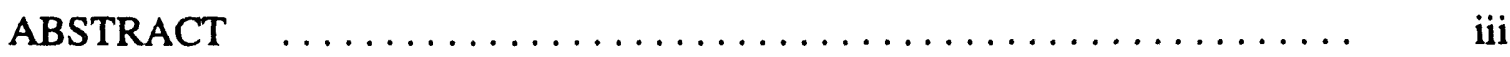

1. INTRODUCTION $\ldots \ldots \ldots \ldots \ldots \ldots \ldots \ldots \ldots \ldots \ldots \ldots \ldots \ldots \ldots$

2. NEW CAPABILITIES $\ldots \ldots \ldots \ldots \ldots \ldots \ldots \ldots \ldots \ldots \ldots \ldots \ldots \ldots \ldots \ldots$

2.1. Wall Graphite Coverage and Conditioning ............... 5

2.2. Diagnostic Enhancement. .................... 5

2.3. Divertor Cryopump $\ldots \ldots \ldots \ldots \ldots \ldots \ldots \ldots \ldots \ldots \ldots \ldots \ldots, 8$

2.4. Modeling and Analysis $\ldots \ldots \ldots \ldots \ldots \ldots \ldots \ldots \ldots \ldots \ldots . \ldots \ldots$

3. PARTICLE CONTROL EXPERIMENTS. ................ 11

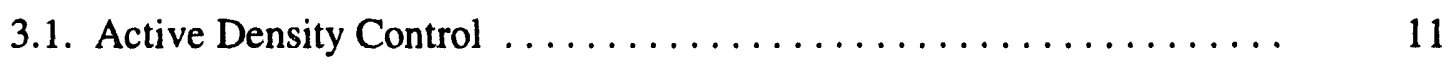

3.2. Helium Transport and Exhaust Studies ................. 13

3.3. Effects of Divertor Pumping on Core and SOL Parameters . . . . . . . 14

3.4. Evolution of Wall Particle Load . . . . . . . . . . . . . . . . . . 19

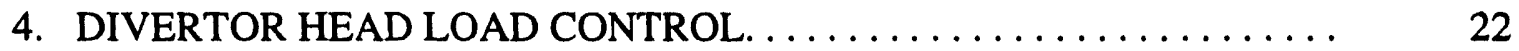

4.1. Radiative Divertor Experiments .................. 22

4.2. Puff and Pump Experiments ..................... 23

4.3. Divertor Modification Plans . . . . . . . . . . . . 25

5. PLASMA-SURFACE INTERACTION STUDIES . . . . . . . . . . 29

6. SUMMARY AND CONCLUSIONS $\ldots \ldots \ldots \ldots \ldots \ldots \ldots \ldots \ldots \ldots$

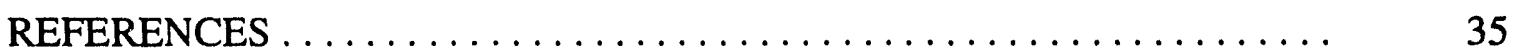

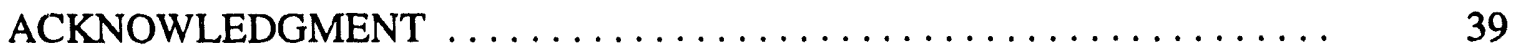




\section{LIST OF FIGURES}

Fig. 1. Inside view of DIII-D vacuum vessel $\ldots \ldots \ldots \ldots \ldots \ldots \ldots$

Fig. 2. Cross section view of divertor cryopump $\ldots \ldots \ldots \ldots \ldots \ldots \ldots$

Fig. 3. Examples of density regulated $\mathrm{H}$-mode plasmas $\ldots \ldots \ldots \ldots \ldots \ldots$

Fig. 4. Helium exhaust in ELMing $\mathrm{H}$-mode plasmas $\ldots \ldots \ldots \ldots \ldots \ldots$

Fig. 5. Electron density and temperature profiles before and after pumping during single-null ELMing $\mathrm{H}$-mode plasmas $\ldots \ldots \ldots \ldots \ldots \ldots \ldots$

Fig. 6. Evolution of current profile during divertor pumping compared with an unpumped shot $\ldots \ldots \ldots \ldots \ldots \ldots \ldots \ldots \ldots$

Fig. 7. Effect of density on divertor heat deposition profile $\ldots \ldots \ldots \ldots \ldots \quad 18$

Fig. 8. Divertor pumping reduces the wall particle inventory $\ldots \ldots \ldots \ldots .20$

Fig. 9. Geometry of $\mathrm{D}_{2}$ puff/pump experiment $\ldots \ldots \ldots \ldots \ldots \ldots \ldots \ldots$

Fig. 10. Radiative divertor cross section $\ldots \ldots \ldots \ldots \ldots \ldots \ldots \ldots \ldots \ldots$

Fig. 11. Variations of radiative divertor geometry $\ldots \ldots \ldots \ldots \ldots \ldots \ldots$

Fig. 12. DiMES sample transfer system $\ldots \ldots \ldots \ldots \ldots \ldots \ldots \ldots \ldots \ldots$

Fig. 13. Erosion of the DiMES sample $\ldots \ldots \ldots \ldots \ldots \ldots \ldots \ldots \ldots \ldots \ldots$ 


\section{INTRODUCTION}

Development of an effective divertor heat control technique is essential for viability of ITER and other future tokamak fusion reactors. For example, ITER is expected to generate $\geq 300 \mathrm{MW}$ of alpha power. Such a large heat load is a severe technical challenge, especially when coupled with a predicted very large erosion rate of the divertor target. Fortunately, there are several promising, albeit yet untested, concepts for dispersing the divertor heat load and reducing the target plate erosion rate to acceptable levels. Because of the importance of these problems, during the past two years we have been devoting an increasing portion of DIII-D program effort to understanding and developing techniques for divertor heat load control. We have carried out experiments on reducing the divertor heat load by both $\mathrm{D}_{2}$ gas puffing and impurity injection (Petrie [1], Allen [2]) and have obtained nearly detached divertor plasmas in high powered $\mathrm{H}$-mode plasmas. Encouraged by the results of the particle control and radiative divertor experiments, we have embarked upon a program to develop and experimentally evaluate radiative divertor concepts for applications to future high powered long pulse devices.

Particle control is also an important issue for the next generation tokamaks. Operating ITER at $1500 \mathrm{MW}$ of fusion power produces about $15 \mathrm{Torr} \cdot 1 / \mathrm{s}$ of helium ash, which requires a fuel particle removal rate of about 100 Torr.1/s. Furthermore, in DIII-D and several other existing tokamaks particle control is needed for systematic investigations of heat and particie transport and if current drive. We have approached the problem of particle control from two directions. First, we use various wall conditioning techniques to passively reduce impurity influx and minimize plasma fueling by particles desorbed from the vessel walls. Thus, last year, we increased the vessel graphite 
coverage to $100 \%$ and improved preconditioning of the graphite tiles; as a result we obtained VH-mode plasmas without boronization (Jackson $[3,4])$. Second, we use divertor pumping for active density control, particularly in the H-mode plasmas. The Advarced Divertor cryopump was installed and operated (Mahdavi [5], Menon [6], Smith [7], Schaubel [8]). With the aid of divertor pumping, for the first time, we succeeded in regulating the density of $\mathrm{H}$-mode plasmas (Mahdavi [9]) and conducted a systematic study of the dependence of energy confinement and particle transport on density in H-mode plasmas (Schissel [10]). Using the cryopump we also demonstrated effective helium exhaust (Wade [11]) from ELMing H-mode plasmas.

The problems of divertor heat exhaust and particle control are inherently coupled to materials issues and must be studied self consistently. A large heat flux to the divertor target demands a thin target, which is in conflict with the requirement of a thick target for a long erosion life time. The choice of divertor material is complicated by the nonlinearity of the plasma-surface interactions. The nonlinearity stems from the fact that erosion rate of the target plates depends strongly on the parameters of the impinging plasma, while plasma parameters are modified by particles originating from the target plate. Thus it is essential to investigate the erosion of target plate materials in-situ. To this end we have built and installed a divertor sample transfer system, DiMES (Wong [12], Bastaz [13]).

In this paper we present an overview of the DIII-D boundary physics experiments during the past two years and a plan for future major modification of the machine for radiative divertor studies. The paper is organized in the following manner: New hardware and software capabilities since the last PSI conference, which include the new vessel armor, the cryopump, and new bolometry and IR thermography, are described in Section 2. Section 3 is devoted to particle transport and control topics, including density control in $\mathrm{H}$-mode, the effect of divertor pumping on core and divertor plasma parameters, and helium transport and exhaust experiments. The radiative divertor experiments 

on the DIII-D Tokamak

and plans for a future modification of the DIII-D with a semi-closed divertor are covered in Section 4. In Section 5 we describe the first experimental erosion measurement data, using the DiMES sample transfer system. 


\section{NEW CAPABILITIES}

\subsection{Wall graphite coverage and conditioning}

Low recycling and low impurity influx are necessary to carry out the DIII-D experimental program, and there has been a continued effort to achieve these conditions. During the 1993 campaign, first wall graphite coverage was increased from $40 \%$ to $90 \%$. Presently, as shown in Fig. 1 [Picture from machine interior] except for port openings, the entire plasma facing surface of the DIII-D is covered with graphite tiles. We also removed and sand blasted the surface of all existing graphite tiles, in order to remove metallic impurities deposited on the surfaces from previous operations. Both old and new tiles were vacuum baked to $800^{\circ}-1000^{\circ} \mathrm{C}$ before installation. Once installed, these tiles were conditioned by baking at $400^{\circ} \mathrm{C}$ with nearly pure helium glow conditioning, eliminating the older practice of deuterium glow or pulsed discharge cleaning. These changes decreased the metallic and low $\mathrm{Z}$ impurity content of the plasma substantially compared with the previous year. H-mode was obtained on the fourteenth shot after startup, and for the first time VH-mode was obtained without boronization (Jackson [3]).

\subsection{Diagnostic enhancements}

We expanded and enhanced the diagnostic sets for measuring plasma radiation and heat flow to various surfaces. New diagnostics include two 24-channel bolometer arrays (Leonard [14]), that cover the entire plasma with views optimized to localize the divertor radiation, and new IR cameras (Hill [15]) that measure power lost to the inner wall and ceiling as well as the divertor floor. With these improved diagnostics we now account for $\geq 85 \%$ of the power injected into ELMing DIII-D discharges. Power loss from the core is 


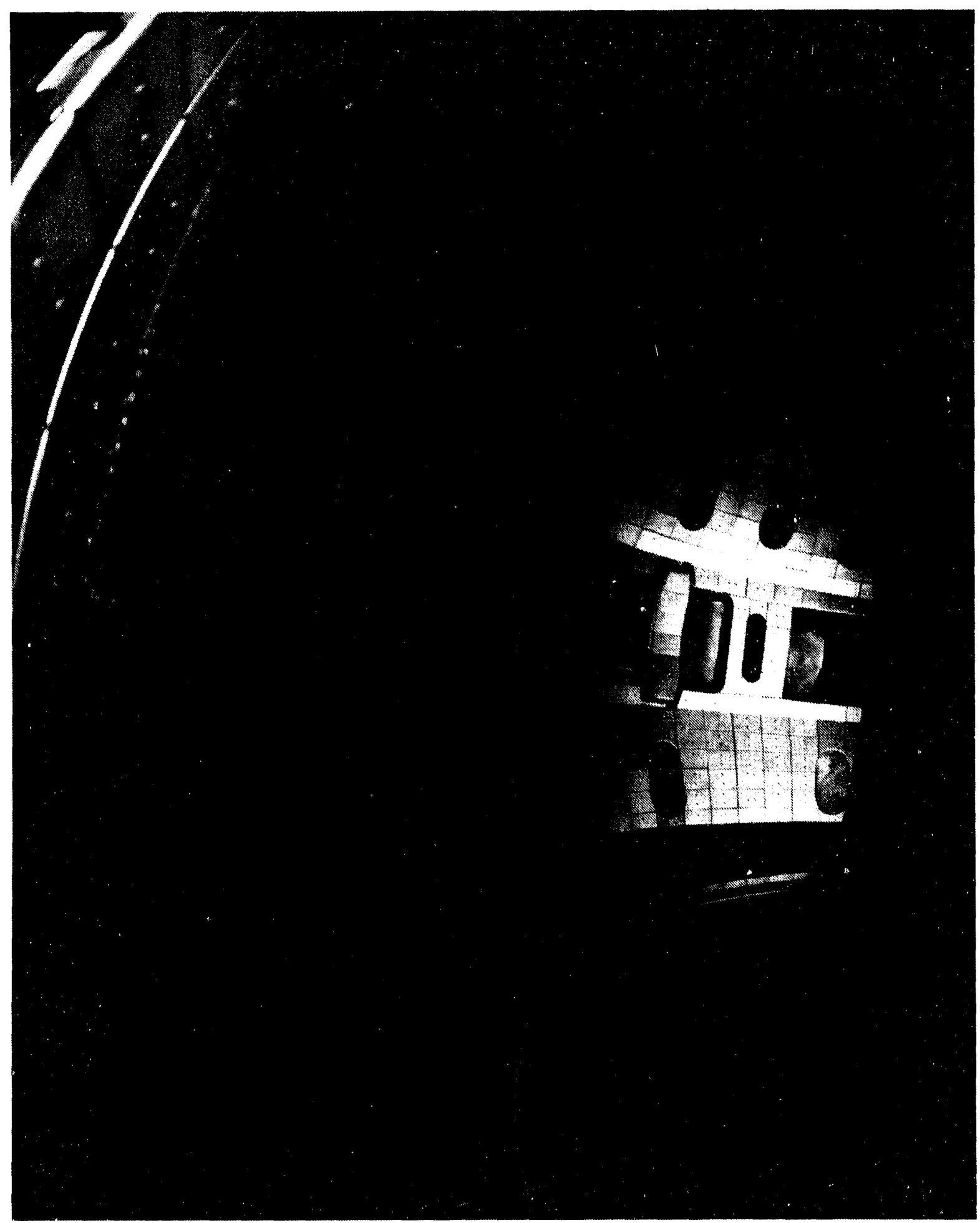

FIG. 1. Inside view of DIII-D vacuum vessel. 
measured through core radiation, and from the divertor via heating of the target surface, $P_{\text {plate, and local radiation, }} \mathrm{P}_{\mathrm{rad}}$. For standard single-null ELMing plasmas power loss is dominantly in the divertor. Less than $20 \%$ of the injected power is lost through core radiation, with the rest flowing to the SOL. Typically the outboard $P_{\text {plate }}$ is 4-6 times greater than the inboard, however when adding $\mathrm{P}_{\text {plate }}$ and $\mathrm{P}_{\text {rad }}$ for each divertor leg separately we find this ratio is reduced to $\leq 1.5$. Gas puffing for radiative divertor experiments does not change the in/out total power ratio, but decreases $\mathrm{P}_{\text {plate }}$ in the outboard leg by increasing $\mathrm{P}_{\text {rad. }}$

Asymmetries in the boundary layer heat flux and scrape-off layer currents are being studied in DIII-D because of the important implications they hold for predictions of divertor heat load for future devices and for assessing the overall power balance of the discharge. Three toroidally distributed IR cameras and a toroidal set of tile current monitors located at three radial positions in the lower divertor are used in this study (Evans [16]). Toroidal and poloidal asymmetries are commonly observed in the upper and lower divertor heat flux. Divertor heat flux asymmetries are characterized by toroidal variations in the radial profile (i.e., multiple peaks at some toroidal locations and single peaks at others) while SOL currents often have a bipolar toroidal structure with characteristics which depend strongly on the plasma parameters. Large asymmetries are always observed in plasmas with locked modes, while smaller asymmetries are sometimes observed in plasmas without locked modes. In plasmas without locked modes, the peakto-peak separation of double peaked divertor heat flux profiles and the toroidal phase of the SOL current distribution depend sensitively on IP at constant $\mathrm{B}_{\mathrm{T}}$. These asymmetries are almost entirely eliminated during radiative divertor operations. In VH-mode the asymmetries are initially smaller than in $\mathrm{H}$-mode but grow (or rotate) slowly until they are comparable to the largest asymmetries observed in DIII-D (i.e., during locked or quasi-stationary modes). During the next experimental period we will concentrate our efforts on identifying the cause of the asymmetries. 


\subsection{Divertor cryopump}

A primary goal of the DIII-D Advanced Divertor Program (ADP) (Mahdavi [5]) is development of an effective technique for density control in DIII-D H-mode plasmas and for future devices. A key element of the ADP is an in-vessel cryopump. The cryopump, shown in Fig. 2(b), was installed in early in 1993. The pump consists of an inner tube at liquid $\mathrm{He}$ temperature, a $\mathrm{LN}_{2}$-temperature radiation shield and an outer ambient-temperature shell. The pump is toroidally continuous mechanically and electrically to minimize disruption induced voltages between the pump and the vessel wall. The pumping speed of the system was measured (Menon [17]) in the absence of a plasma for various gases by continuously puffing gas into the vessel at a known rate and measuring the steady-state pressure reached in the pump plenum. Here the pumping speed is defined as the ratio of particle throughput to the static pressure baffle pressure. The pumping speed defined in this manner is $\approx 40,000 \mathrm{l} / \mathrm{s}$ at a pressure of $5 \mathrm{mTorr}$ of $\mathrm{D}_{2}$ and is a slightly increasing function of pressure. Pulsed heat loads of up to $300 \mathrm{~W}$ did not have a measurable effect on the pumping speed. Helium pumping was achieved by depositing a thin layer of argon frost(roughly $4 \times 10^{22}$ atoms $/ \mathrm{m}^{2}$ ) on the helium-cooled surface, giving a measured pumping speed of helium of $12,000 \mathrm{l} / \mathrm{s}$. More details on the design, construction and the initial pumping experiments can be found in earlier publications (Menon [6], Smith [7], Schaubel [18], Mahdavi [19], Laughon [20]). The results of divertor pumping experiments are summarized in Section 3.

\subsection{Modeling and analysis}

Numerical models of the divertor plasma are essential for both analysis of the data and predictive calculations. We use the SOL fluid codes UEDGE (Rognlien [21]), Braams (B.2 [22], and the DEGAS (Heifetz [23]) Monte-Carlo neutral code for analysis of the divertor plasma: (Porter [24], Fenstermacher [25]). UEDGE, which replaced the 
COMPLETE CARBON-TILE COVERAGE

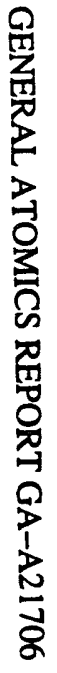

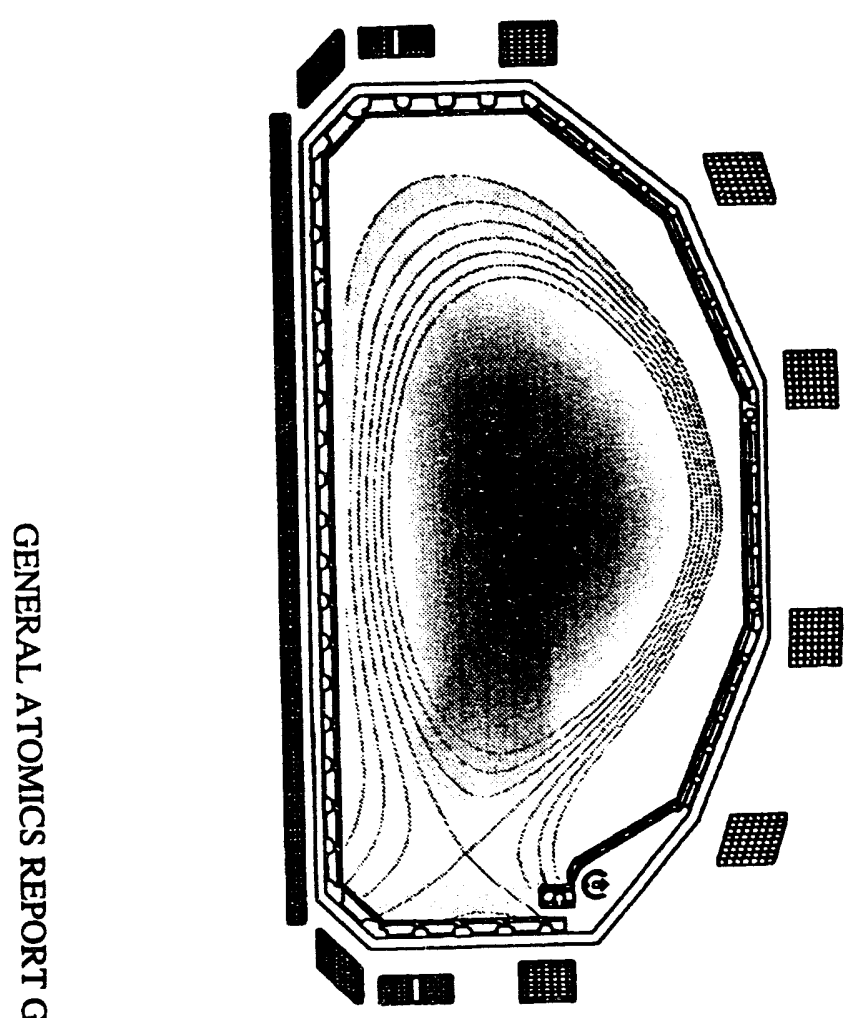

\section{CRYOPUMP UNDER DIVERTOR BAFFLE}



FIG. 2. Cross section view of divertor cryopump. For effective pumping the outer divertor strikepoint is placed at the opening to the pumping plenum. 
older LEDGE code, is more suitable for introducing new physics and impurity packages. New capabilities of UEDGE include a self consistent treatment of impurities and impurity radiation, a two group neutral model, and improved numerics to allow use of finer grids. We are also developing a Monte-Carlo impurity transport code, MCI (Lippmann [26]) which is intended to be used iterativeiy with the UEDGE code. 


\section{PARTICLE CONTROL EXPERIMENTS}

\subsection{Active density control}

In typical $\mathrm{H}$-mode plasmas, the most common good confinement regime of tokamaks, the plasma density increases rapidly after the transition to the H-mode. In DIII-D, the plasma density eventually saturates at a level proportional to the plasma current, $\mathrm{n}_{\mathbf{e}}$ $\left(10^{20} \mathrm{~m}^{-3}\right) \approx 0.6 \times$ IP $(\mathrm{MA})$. This co-linearity prevented an independent determination of scaling of the plasma confinement with $n_{e}$ and $I_{p}$. Furthermore, the ultimate density reached in $\mathrm{H}$-mode is too high for planned DIII-D current drive experiments. In the past, helium glow and other wall conditioning techniques have been used successfully in controlling the plasma density in L-mode (Jackson [27]); however, similar efforts on $\mathrm{H}$-mode plasmas have produced only small effects. Using the divertor cryopump, we succeeded, for the first time, to control the density of $\mathrm{H}$-mode plasmas independent of the plasma current. In general, divertor pumping is found to be more effective in $\mathrm{L}$-mode than in $\mathrm{H}$-mode because of the comparatively broader and denser SOL of L-mode plasmas. Typically in L-mode plasmas the density decay time constant is $\tilde{<} 100$ ms. In contrast, in ELMing $\mathrm{H}$-mode plasmas, the density decay time constant is usually $0.5-1 \mathrm{~s}$.

We used a combination of real-time digitally controlled gas puffing and divertor pumping to regulate the plasma density (Mahdavi [19]). The pumping rate is controlled by magnetically adjusting the position of the divertor strikepoint relative to the pumping plenum aperture. Figure 3 displays examples of $\mathrm{H}$-mode plasmas where the plasma density was varied by a factor of 2 at constant $I_{p}$ and, conversely, $I_{p}$ was varied by 

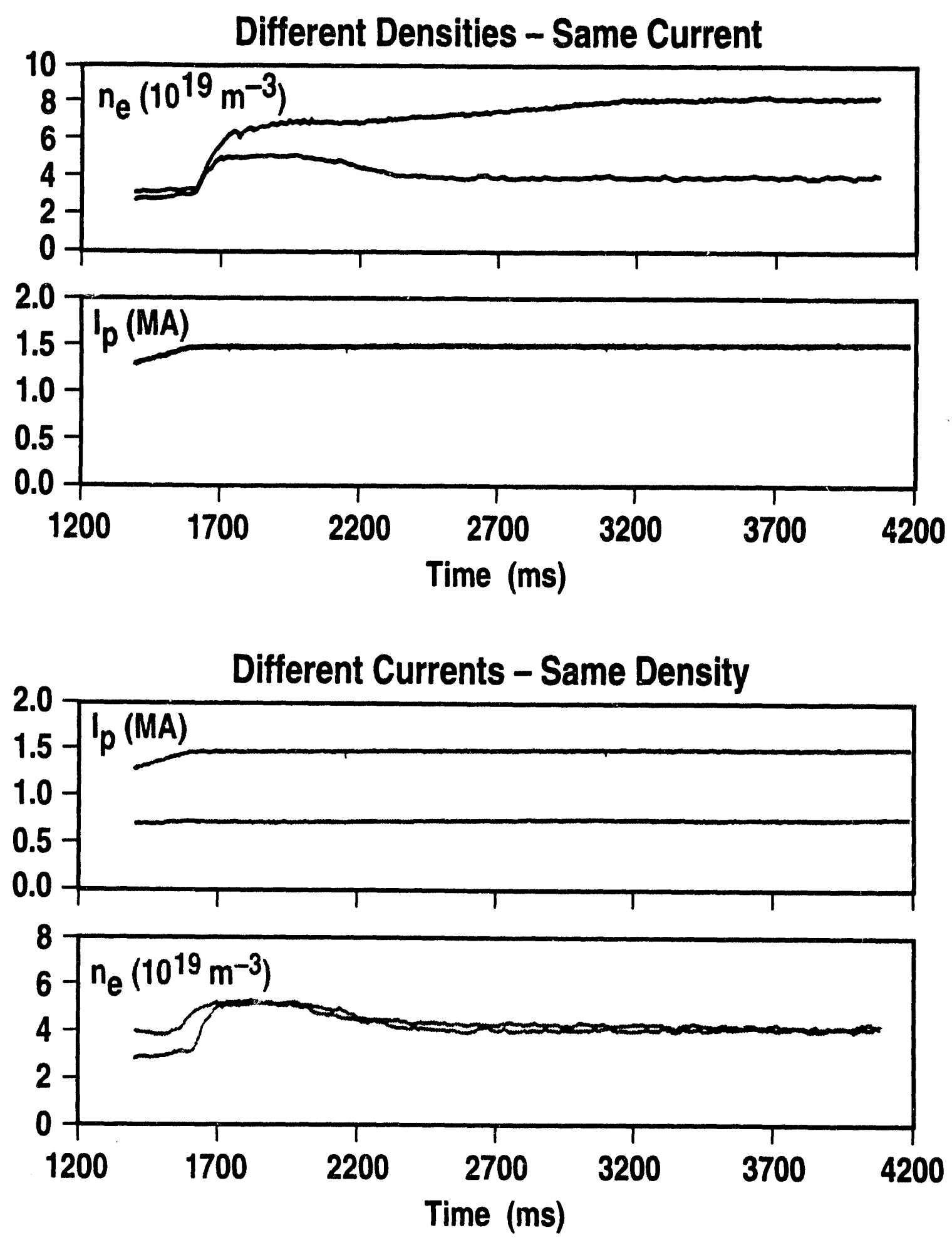

FIG. 3. Examples of density regulated $H$-mode plasmas. (a) Shots with the same plasma current and different densities. (b) Shots with same density and different currents. Pumping rate was controlled by adjusting the position of the outer strikepoint relative to the opening of the pumping plenum. 
constant density over a range of a factor of two. In most cases, the lowest $\mathrm{H}$-mode electron density obtained was determined by transport and recycling as expected. However, in some shots with moderately high beta, growth and locking of a 2/1 MHD mode limited the lowest attainable density (see below). Having the plasma current and density decoupled, we were able to determine that $\mathrm{H}$-mode confinement, similar to $\mathrm{L}$-mode, is only a weak function of $n_{e}$ and increases almost linearly with $I_{p}$ (Schissel [10]).

\subsection{Helium transport and exhaust studies}

We have studied helium transport (Hillis [28], Wade [29]) in a variety of plasma conditions and demonstrated active exhaust of helium using the divertor cryopump (Wade [11]). To date helium studies have focused on ELMing $\mathrm{H}$-mode plasmas. Studies of helium transport on DIII-D using time resolved helium profile measurements have shown that the ratio of the local helium diffusivity to the local heat conductivity increases with increasing ELM frequency and is insensitive to changes in plasma current - an important result in extrapolating present results to ITER, which has a projected plasma current up to a factor of 10 higher than present-day devices. During active helium exhaust studies using an argon-frost divertor cryopump, the core helium content was observed to be exhausted from the system with a time constant of $\approx 8-12$ energy confinement times, within the range required for helium exhaust in a fusion reactor (see Fig. 4). It is also observed that the helium density in the plasma center responds quickly to the onset of pumping and the entire helium density profile decays with the same time constant. While not yet definitive, these observations suggest that the removal of helium in these experiments is limited by the divertor exhaust efficiency and not by the rate at which helium is transported from the plasma core to the plasma edge. Since the ELM 


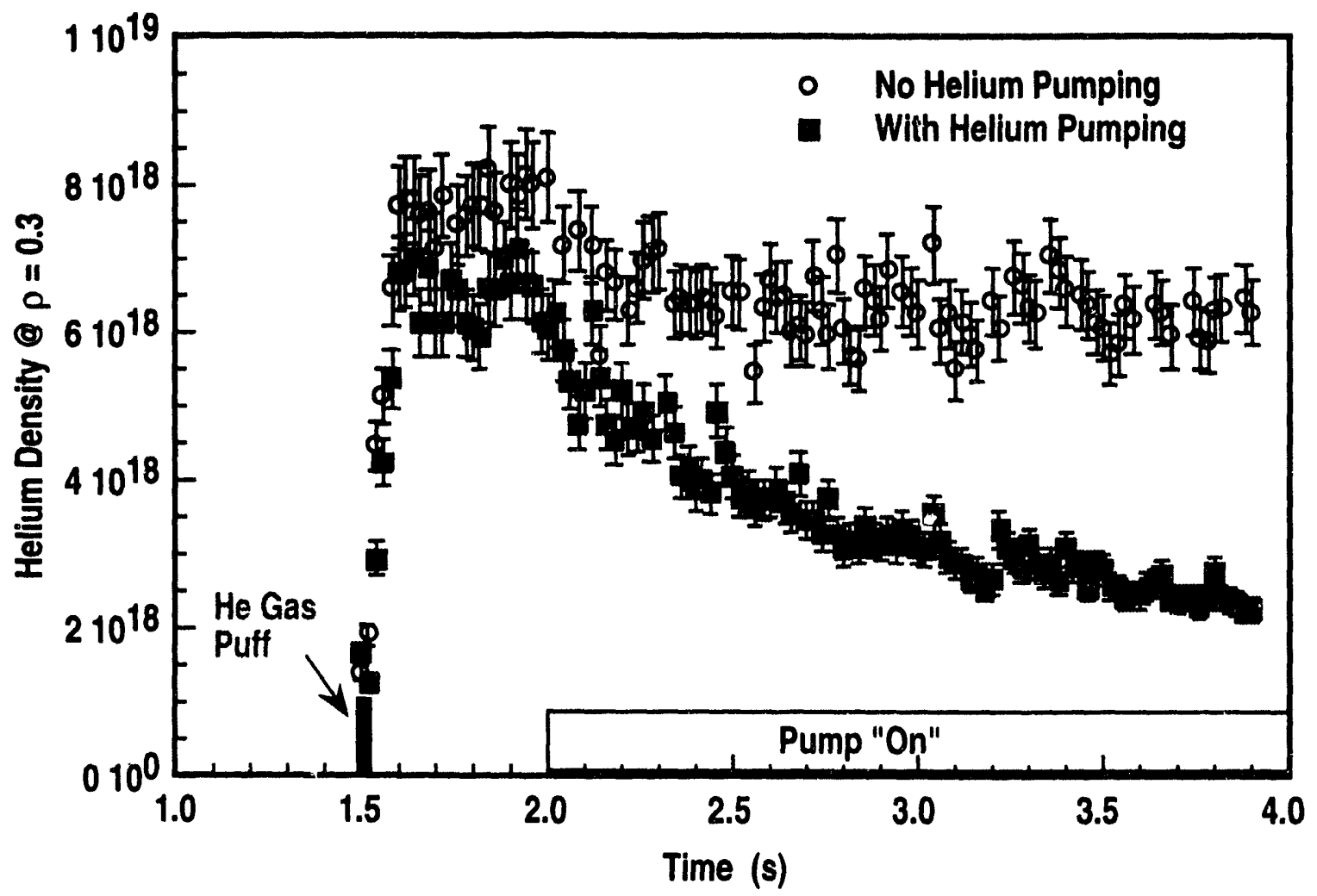

FIG. 4. Helium exhaust in ELMing H-mode plasmas. Core helium density decay time constant is $\lesssim 12 \tau$ E.

frequency in the helium exhaust studies outlined above was fairly low $(\sim 40 \mathrm{~Hz})$, it is expected that as the ELM frequency is increased, an even lower value can be obtained. Finally, there has been no indication of preferential accumulation of helium relative to the electron density in any discharge condition studied to date, suggesting a strong link between helium and deuterium particle transport in DIII-D.

\subsection{Effects of divertor pumping on core and SOL parameters}

Divertor pumping has profound effects on the core plasma parameters. Pumping reduces plasma density and radiation and increases the ion and electron temperatures. As the core density decreases, electron and ion temperatures increase such that the plasma stored energy remains nearly unchanged. In most cases $T_{i}$ increases more than $T_{e}$ since, 
in the parameter range of these plasmas, most of the neutral beam heating power is delivered to the plasma ions and both lower density and higher temperature reduce the energy exchange rate between ions and electrons. Pumping also modifies the density, temperature, and current profiles. Typically in $\mathrm{H}$-mode plasmas, these profiles evolve for the first two seconds after the start of pumping before reaching a quasi steady state. Figure 5 shows a comparison of $n_{e}$ and $T_{e}$ profiles of pumped and unpumped shots measured at $\mathrm{t}=4.1 \mathrm{~s}, 2.5 \mathrm{~s}$ after the start of pumping.

Divertor pumping reduced the electron density gradient and increased the electron temperature gradient just inside the separatrix. Reduced recycling during divertor pumping can explain the change in the density gradient in this region, although a concurrent change in particle transport coefficients can not be ruled out. At $\rho \leq 0.6$ in the core plasma, the density gradient is nearly a factor of two higher in the higher density plasma. Since in this region the recycling source is insignificant while the neutral beam particle deposition profile is much broader at the higher density, it follows that the particle transport time scale in this region increases non linearly with density. We should note that a similar peaking of the density profile was not observed in the low current plasmas.

Divertor pumping modifies the current profile in the core plasma. The effect on the current profile is indirectly through changes in the electron temperature, the plasma pressure, and the neutral beam deposition profiles. Thus all components of the current drive, namely inductive, bootstrap and neutral beam are affected. As the density and temperature profiles evolve during the first seconds of pumping, so does the current profile. During the evolving phase of some pumping shots, as shown in Fig. 6, the current profile in the vicinity of the $q=2$ surface can become significantly steeper. However, later in the quasi steady state phase of pumped plasmas, current profiles are either similar to or slightly broader than in unpumped plasmas. 


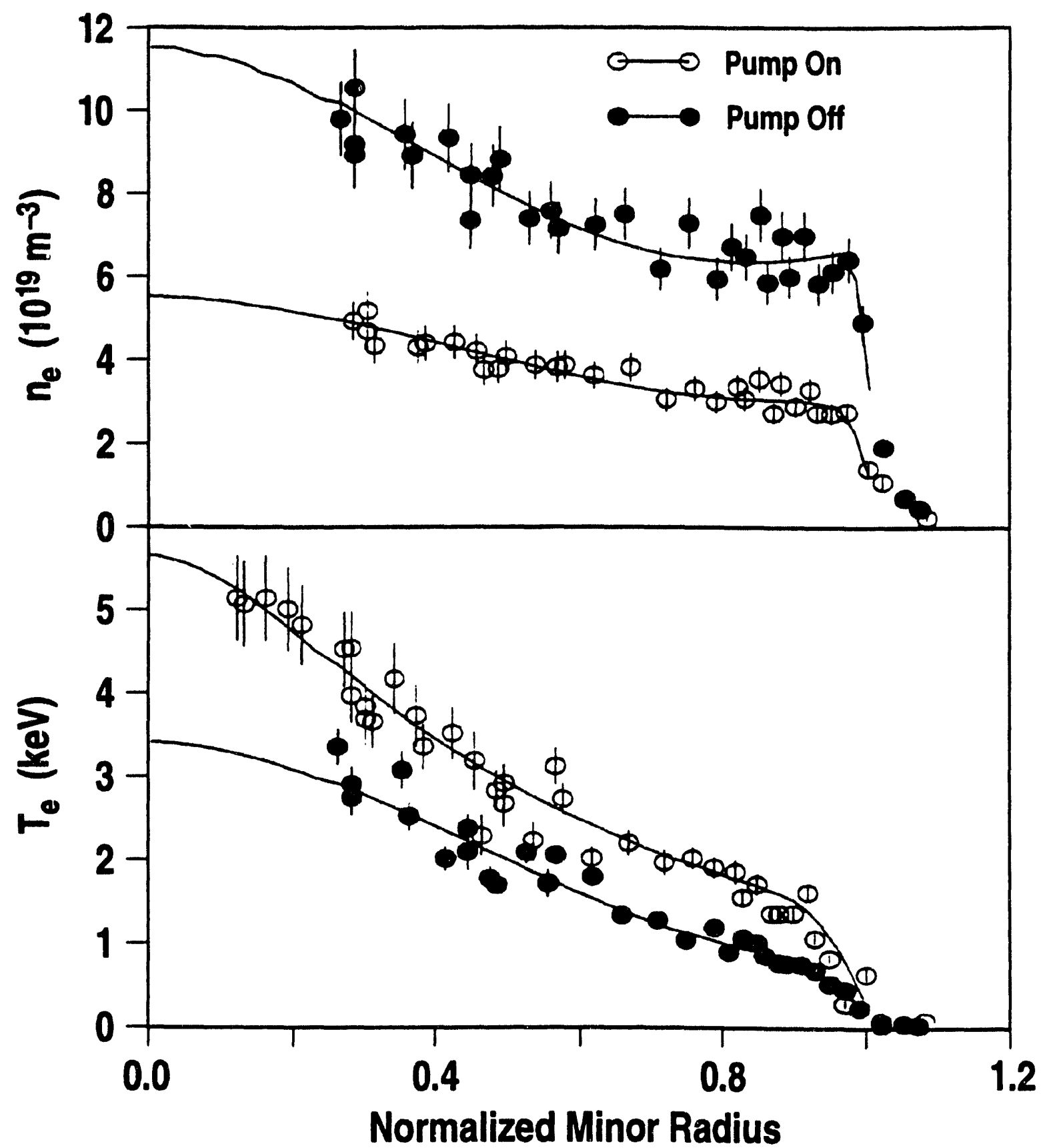

Fig. 5. Electron density and temperature profiles before and after pumping during single-null ELMing $\mathrm{H}$-mode plasmas, $\mathrm{I}_{\mathrm{p}}=1.5 \mathrm{MA}, \mathrm{BT}=2 \mathrm{~T}$.

We have examined the effect of divertor pumping on the SOL and divertor plasma parameters under quasi steady-state conditions (Maingi [30], Mioduszewski [31]). In general, with divertor pumping, the SOL density far upstream from the divertor and the 


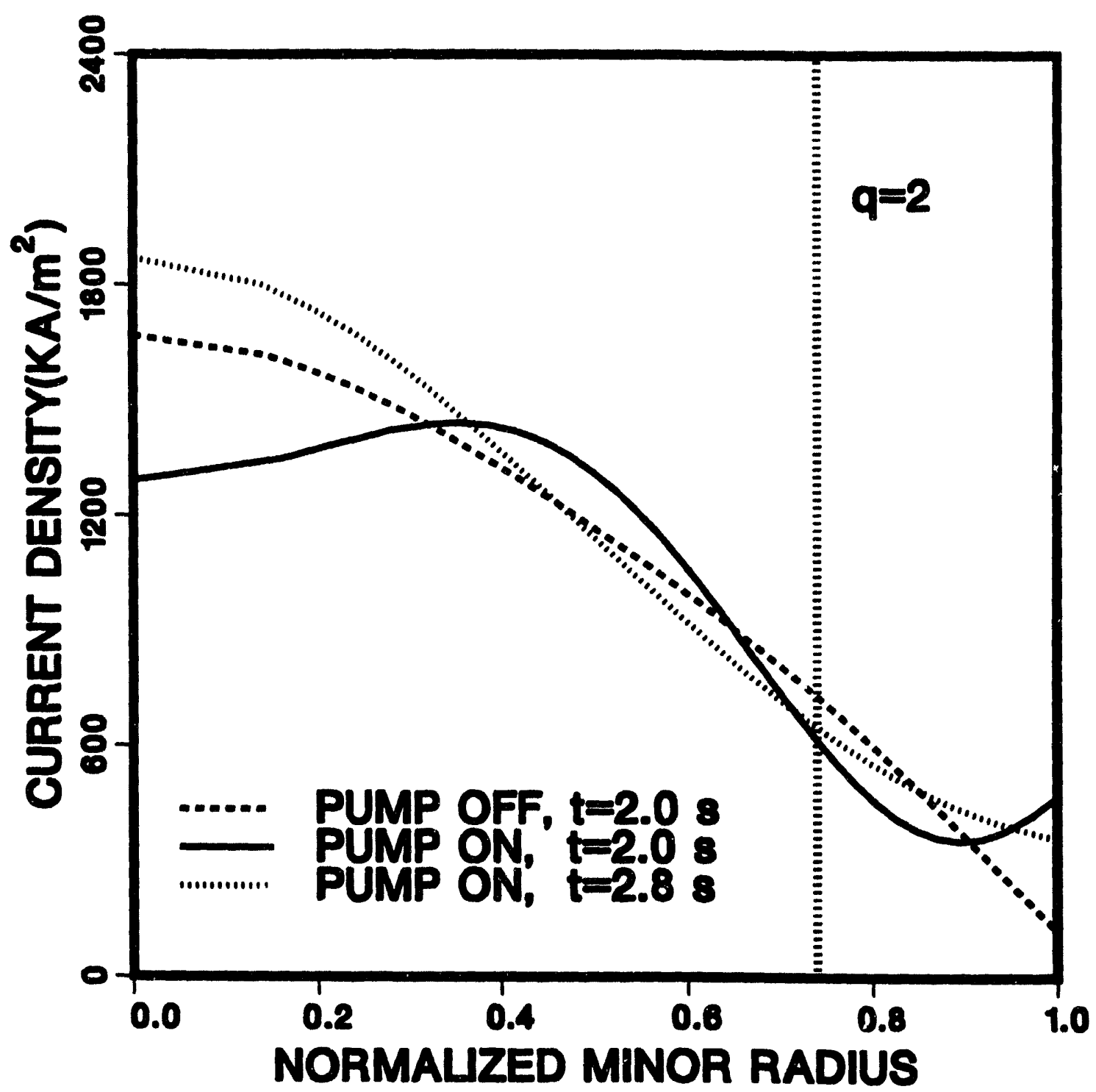

Fig. 6. Evolution of current profile during divertor pumping compared with an unpumped shot. During some pumped shots (solid curve) the current ofile in the vicinity of $q=2$ surface steepens, causing growth of a 2/1 MHD mode.

$D_{\alpha}$ line intensities at all poloidal positions decrease. With pumping the heat deposition profile at the inboard target sharpens, peak $\mathrm{T}_{\mathrm{e}}$ increases, and the total heat load increases. During pumping the outboard target can not be viewed; however, since the increase in inboard divertor target power, as shown in Fig. 7, approximately equals the reduction in 


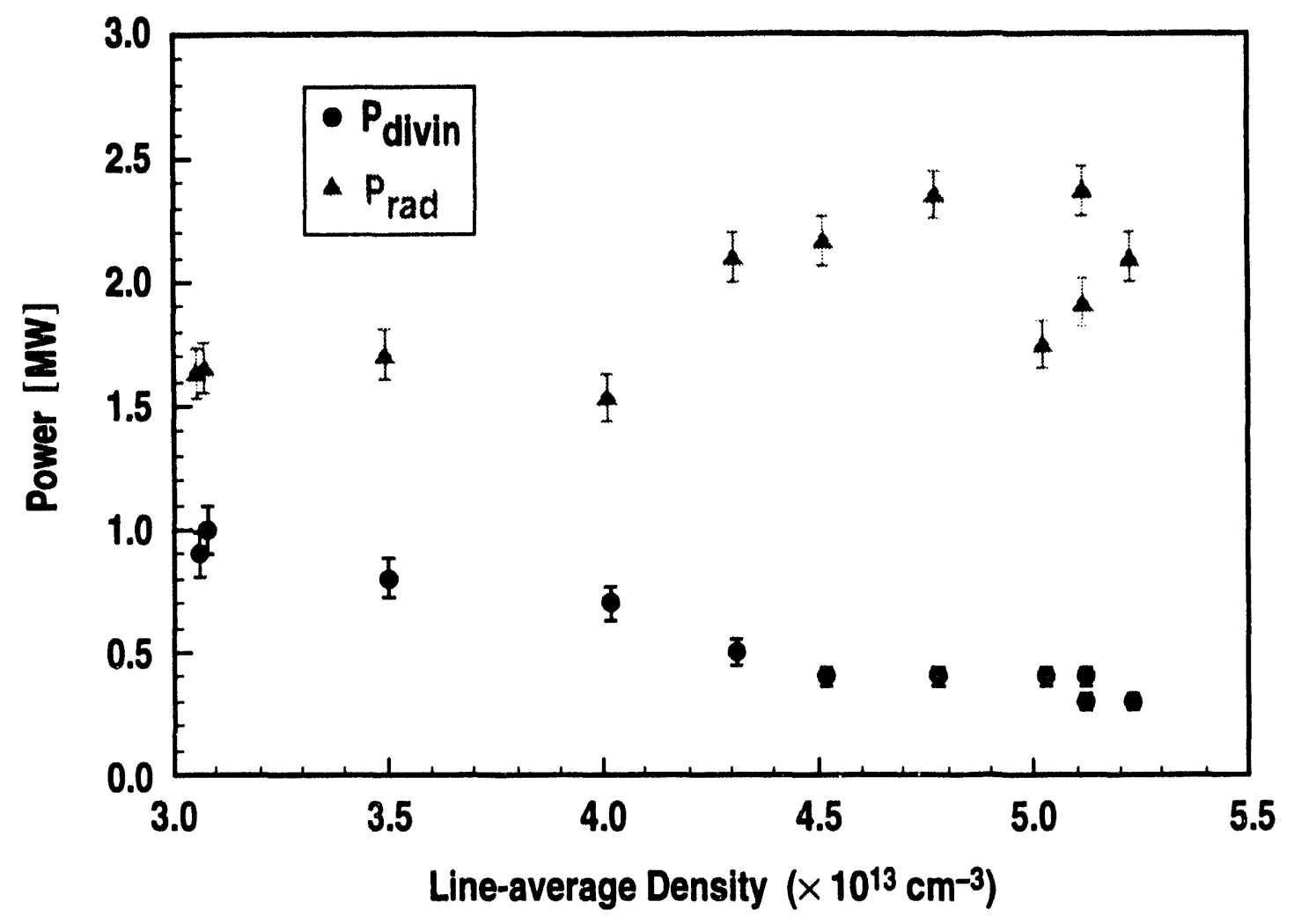

Fig. 7. Effect of density on divertor heat deposition profile. Heat flux to the inner divertor target increases with decreasing density.

the total core and divertor radiation, we deduce that the inner to outer divertor power ratio has increased. When the separatrix is placed at its optimum position for particle exhaust (at this position the line-average electron density is $3 \times 10^{19} \mathrm{~m}^{-3}$ or $50 \%$ of its "normal" $\mathrm{H}$-mode value), the heat load on the inner divertor approximately doubles. These results suggest that the large heat flux imbalance between the inner and outer divertor strike zones, normally observed in divertor experiments (Leonard [14], Maingi [30]), is at least partly due to radiative losses in front of the divertor strike zone. Thus, with differential pumping and gas puffing it may be possible to control the inner to outer heat flux ratio. 


\subsection{Evolution of wall particle load}

Normally with helium glow discharge cleaning (Jackson [32]), the graphite divertor and vessel armor behave as a strong particle sink. This is demonstrated in Fig. 8(a), Shot 1 where in the absence of significant pumping, plasma particles account for about only $10 \%$ of the injected cold gas and NBI particles. By the end of this shot, the wall particle inventory, as deduced from the difference between the external particle sources and sinks, has increased by nearly 150 Torr $\ell$. Most of the wall particle loading occurs during the $I_{p}$ and density ramp up phase. Our data show that the distribution of particles between the wall and the plasma depends not only on initial wall condition but also on the conditions of the plasma (Mahdavi [9], Mahdavi [19]). This is demonstrated in Fig. 8(b) where the divertor pump was activated at $\mathrm{t} \cong 1600 \mathrm{~ms}$, during a shot otherwise identical to that of Fig 8(a). In the latter shot the wall particle inventory decreases monotonically during divertor pumping. This observation is understood by noting that during pumping the plasma particle flux to the divertor target is reduced thus altering the dynamic equilibrium between the wall and the plasma.

It is important to note that, independently of the initial wall conditions, after $\approx 3 \mathrm{~s}$ of divertor pumping, the pump exhaust rate is approximately equal to the neutral beam particle source, and as this observation suggests, the initial wall condition does not significantly affect the lowest attainable density when pumping is applied for more than $\approx 3 \mathrm{~s}$. The observed shot time constant fort decay of the wall particle source indicates that the particles originate from a shallow region near the graphite surface of a depth no more than a few tens of angstroms. 

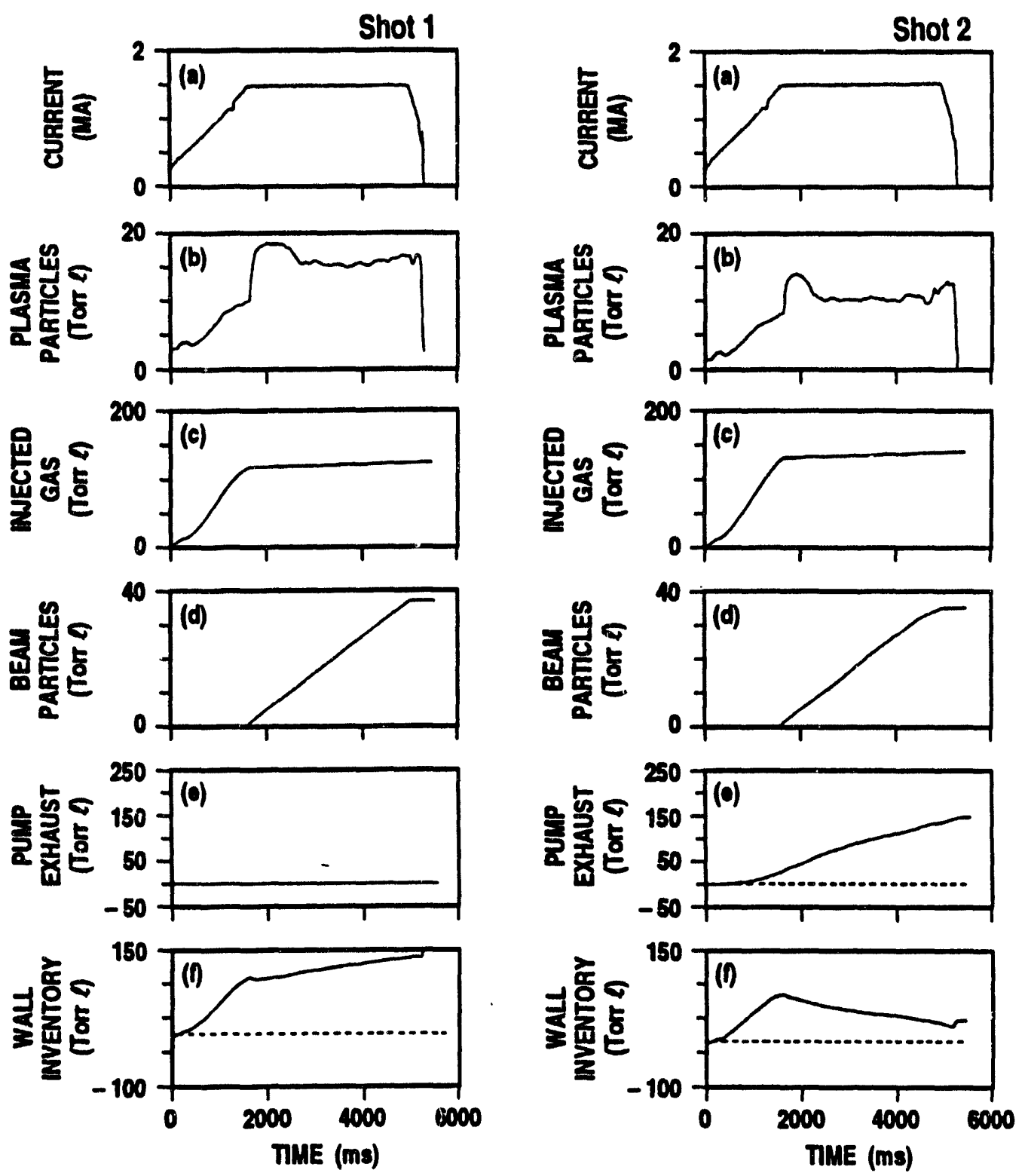

FIG. 8. Divertor pumping reduces the wall particle inventory. (a) In absence of pumping, wall particle inventory increases throughout the shot. (b) With pump activated, wall particle inventory decreased shortly after the $\mathrm{L}-\mathrm{H}$ transition. 


\section{CASE 1}

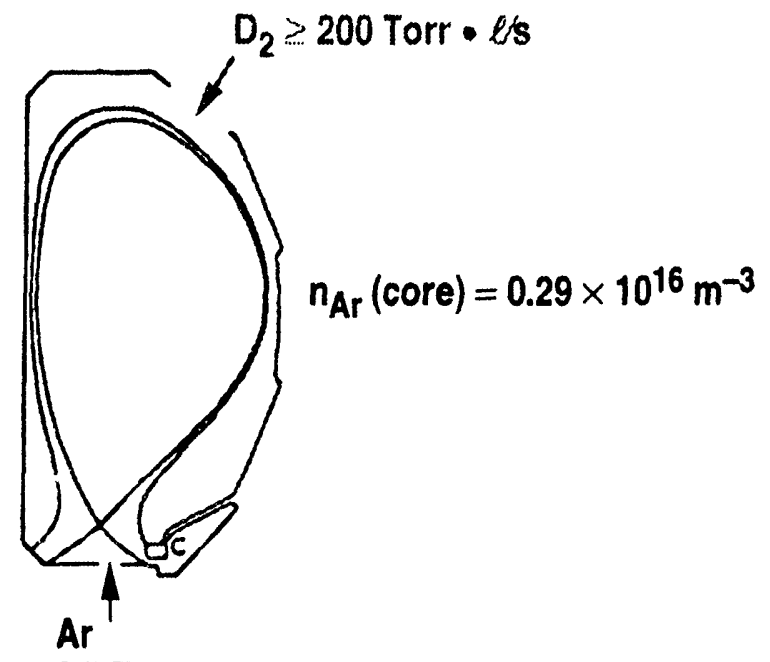

0.5 Torr $\bullet$ e's
CASE 2

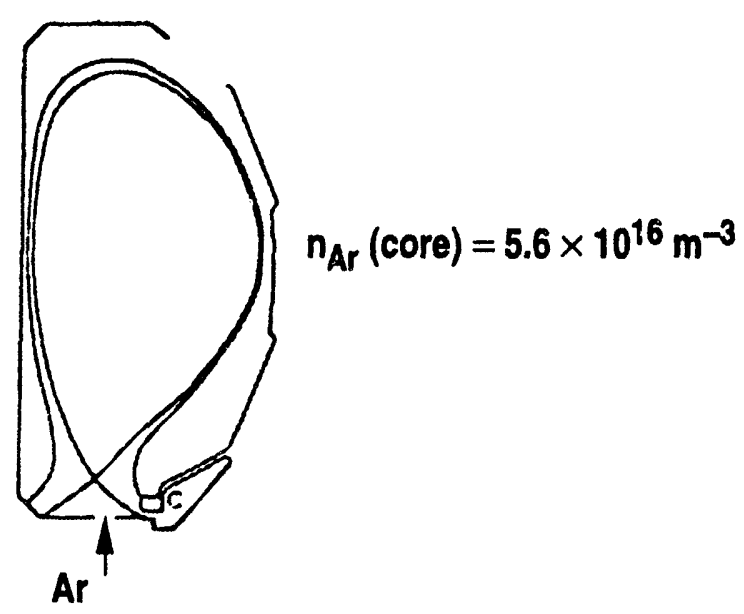

\section{CASE 3}

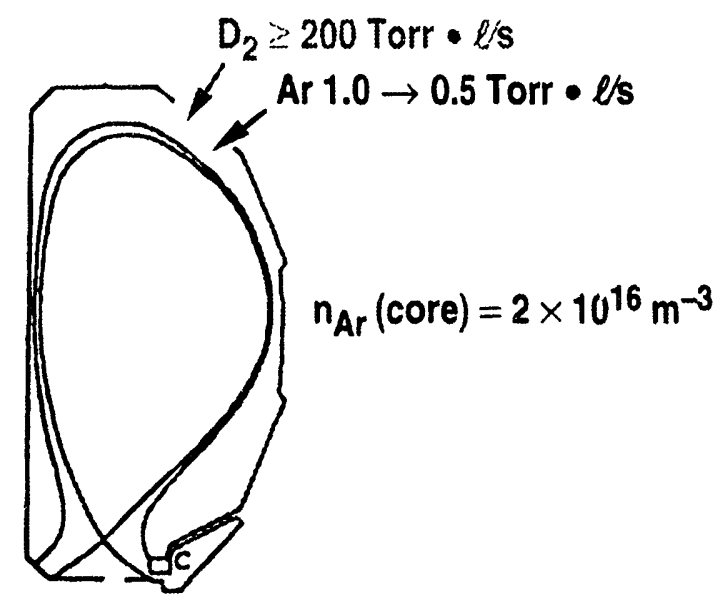

CASE 4

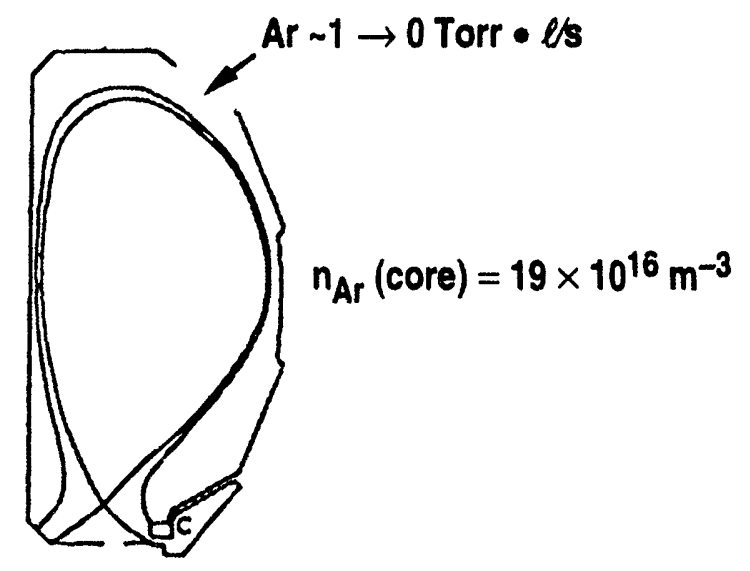

Fig. 9. Geometry of $D_{2}$ puff/pump experiment 


\section{4. [IIVERTOR HEAT LOAD CONTROL}

\subsection{Radiative divertor experiments}

It has been proposed that impurity and hydrogen radiation can be used to significantly reduce the diverlor target heat load in future devices (Ohyabu [33], Shimada [34], Ohyabu [35], Allen [36]). The success of these techniques depends on our ability to contain the radiation to a region mostly outside of the confinement zone such that the core confinement does not degrade. The spatial distribution of the radiation can be affected by the choice of radiating specie(s), the choice of the plasma parameters, and SOL flows which entrain impurities. During the past year we have conducted radiative divertor experiments in ELMing $\mathrm{H}$-mode plasmas using both $\mathrm{D}_{2}$ injection and neon injection. Deuterium injection in:reases divertor radiation by virtue of increasing density and lowering temperature in the vicinity of the target plates. As a result, both the radiation due to both recycling particles and intrinsic impurities (mainly carbon in these experiments) increases. For typical DIII-D parameters neon radiates efficiently both in the divertor plasma and in a thin "ntantle" region just inside the separatrix. We also studied the effect of forced SOL flows on impurity content of the core plasma.

As presented elsewhere (Petrie [1], Allen [2]) we have measured a 5-10 fold reduction in the divertor heal: flux by puffing deuterium or impurities into the divertor region. In both cases, we observe a localized radiation zone near the X-point with 48-channel bolometer array. During neon puffing, we also observe a radiating mantle just inside the separatrix in the core plasma; the total radiation in the localized zone near the $\mathrm{X}$-point and the core mantle are roughly equal. During this time, the plasma pressure $3 / 2 \mathrm{nekT}_{\mathrm{e}}$ measured at the divertor plate by a Langmuir probe array is less than that measured at the midplane by a moveable Langmuir probe and Thomson scattering; we infer from these 
measurements that plasma momentum is removed \{e.g., by interactions with neutrals (Ghendrih [37])\}. It has been shown by Borrass et al. (Borrass [38]) that momentum loss along the field lines enhances the performance of a radiative divertor. The core confinement time is not changed substantially during the puffing experiments, but there are significant influences on the plasma core: the core density rises with $\mathrm{D}_{2}$ puffing, and the core $Z_{\text {eff }}$ rises with impurity puffing (to $\sim 3$ in the case of neon).

\subsection{Puff and pump experiments}

A steady-state deuterium "puff and pump" technique was developed (Schaffer [39]) which was very effective at reducing the central density of Ar, continuously puffed as a trace impurity. The ELMing H-mode plasmas $\left(\mathrm{f}_{E L M}=30-90 \mathrm{~Hz}\right)$ had $\mathrm{I}_{\mathrm{p}}=1.5 \mathrm{MA}$, $\mathrm{B}_{\mathrm{T}}=2.0 \mathrm{~T}$ and $8.5 \mathrm{MW}$ of neutral beam heating. Figure 9 illustrates the experiment geometry. Deuterium was puffed from two calibrated valves near the top of the plasma while the pump exhausted gas from the outer divertor. Ar was puffed from either the same upper poloidal location as the $\mathrm{D}_{2}$ or under the $\mathrm{X}$-point.

Up to 200 Torr $\ell / s$ of $D_{2}$ were puffed continuously with no degradation of the $150 \mathrm{~ms}$ gross energy confinement time. Such puffing in the absence of pumping disrupts the plasma. The central $\mathrm{n}_{\mathrm{e}}$ and $\mathrm{T}_{\mathrm{e}}$ during puffing were $1.1 \times 10^{20} \mathrm{~m}^{-3}$ and $3.1 \mathrm{keV}$, respectively; without $D_{2}$ puffing they were $0.75 \times 10^{20} \mathrm{~m}^{-3}$ and $4.1 \mathrm{keV}$. Evidence for SOL flow induced by puffing was sought in the Doppler shift of the $529.0 \mathrm{~nm}$ C VI line viewed toroidally by the charge exchange recombination diagnostic, but the measurement uncertainty of $2.5 \mathrm{~km} / \mathrm{s}$ is comparable to the expected 3-10 km/s (estimate very sensitive to flow profile and location in SOL), and no firm conclusion can be drawn.

Quantitative calculation of the Ar concentration was accomplished by adjusting parameters in the MIST impurity transport code to fit measured VUV line intensities viewed tangentially. All four cases in Fig. 10 were well modeled using a constant 


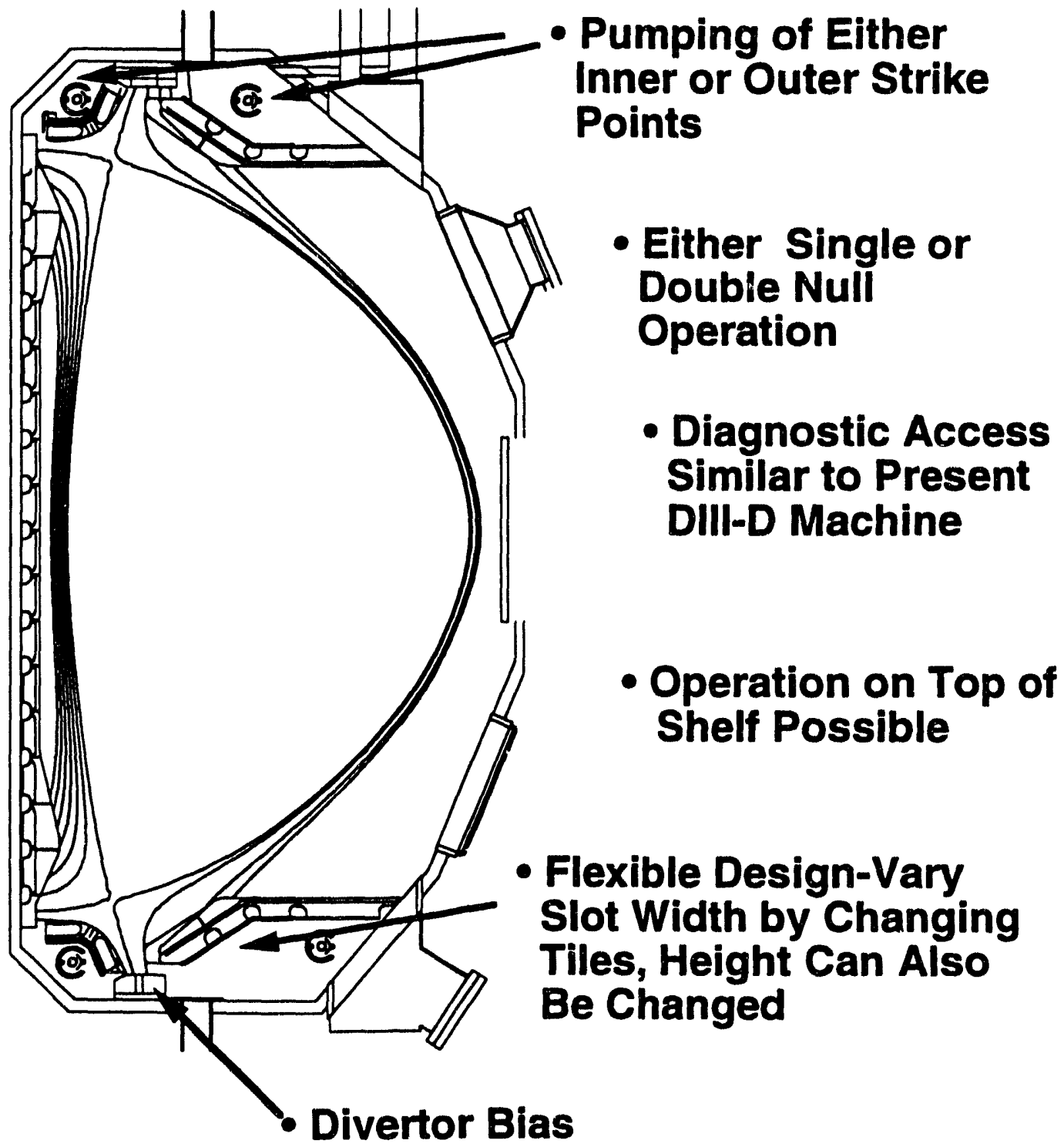

Fig. 10 Radiative divertor cross section.

diffusion coefficient $\left(D=0.25 \mathrm{~m}^{2} \mathrm{~s}^{-1}\right)$ and pinch factor $\left(c_{v}=1.75\right)$, where $v_{\text {pinch }}=c_{v} D$ $(d / d r)\left[\ell n n_{e}(r)\right]$. The main results, summarized in Table $I$, are that $D_{2}$ puffing reduced central Ar density 20-fold during X-point Ar puff and 10-fold during upper SOL Ar puff. Thus, the "puff and pump" technique very effectively reduces core impurities. In future experiments with new divertor diagnostics and higher Ar puffing to radiate more strongly 


\section{TABLE I \\ Puff and Pump MIST Modeling Results}

$\tau_{\mathrm{Ar}}$ is defined as the ratio of the argon ions in the core plasma to the atomic argon puff rate.

\begin{tabular}{lllll}
\hline Case No. & 1 & 2 & 3 & 4 \\
\hline Ar puff (torr $\cdot / \mathrm{s})$ & 0.5 & 0.5 & $\approx 1$ & $\approx 1$ \\
$\mathrm{n}_{\mathrm{Ar}}(0)\left(10^{15} \mathrm{~m}^{-3}\right)$ & 2.9 & 56 & 20 & 190 \\
$\tau_{\mathrm{Ar}}(\mathrm{ms})$ & 1 & 20 & 4 & 40 \\
\hline
\end{tabular}

we will resolve whether the technique preferentially concentrates impurities in the divertor, which is desired for radiative divertor applications, or simply flushes them rapidly out to the pump.

\subsection{Divertor modification plans}

We are using the experience gained in our current (open) Advanced Divertor (AD) to guide the design of a new Radiative Divertor (RD) (Allen [2]) for DIII-D. We observe separately the basic ingredients of an integrated divertor solution in the DIII-D experiments: 1) significant reduction in the divertor heat flux, 2) active density control ( $\mathrm{n}_{\mathrm{e}}$ and helium) with cryopumping, and 3 ) reduced plasma pressure at the divertor plate. The RD design focuses on obtaining these features simultaneously and to provide particle control for enhanced-confinement advanced tokamak discharges. DIII-D experiments (Lazarus [40]) have demonstrated enhanced confinement discharges with $\tau_{E}$ up to 3.6 times the ITER-89P scaling; high triangularity $(\delta \sim 0.8)$ has been demonstrated to be necessary for this performance. High triangularity operation requires moving the separatrix $\sim 30 \mathrm{~cm}$ away from the present pump. Because the pumping rate with such a large separatrix-pump gap is negligible, the pump must be moved inboard for particle control in high triangularity plasmas. The RD pump entrance is placed in the optimum 
location for these advanced tokamak modes and thereby focuses our research on a divertor integrated into an advanced tokamak design.

To minimize the influence on the core plasma while reducing the divertor heat flux, we are designing the RD as shown in Fig. 10 (Allen [2]). The RD allows either single or double-null operation with high triangularity. Baffles are used to isolate the divertor and core regions. The design draws extensively on engineering experience gained to date on the AD for DIII-D: graphite tiles are mounted on water-cooled structures and the cryopump design is identical to that used on the $\mathrm{AD}$. The design is extremely flexible, and will allow modifications based on physics results. The slot geometry can be easily varied by changing the thickness and contour of the graphite tiles (severak week change). The slot length can also be variable (couple month change). SOL biasing to provide $\mathrm{E}_{\mathrm{r}}$ and thereby poloidal drifts for directed particle exhaust is a part of the design (Couture [41], Schaffer [42]). A detailed drawing of the lower divertor for $23 \mathrm{~cm}, 33 \mathrm{~cm}$ and $43 \mathrm{~cm} \mathrm{X}$-point to (outside) target distances is presented in Fig. 11; the upper divertor is similar. The flux surfaces shown are each spaced $0.5 \mathrm{~cm}$ from the separatrix when measured at the plasma outer midplane. The length of field lines from midplane to the divertor target plate in all three cases exceeds $10 \mathrm{~m}$.

We have performed modeling to determine the efficiency of divertor structures in reducing neutral recycling to the core plasma. These calculations indicate that the baffles in the RD design, reduce the core ionization by a factor of 10-15 compared to the completely open divertor (Fenstermacher [43]). Estimates of the recycling from the baffle structures themselves is included in these calculations. From these results, we expect the RD to allow particle control during radiative divertor operation. NEWT-1D calculations (Campbell [44]) (a 1-1/2 D model) indicate that impurity entrainment along field lines for DIII-D conditions should be good. Furthermore, semi-quantitative calculations with NEWT-1D require a small upstream wall to source explain the impurity 


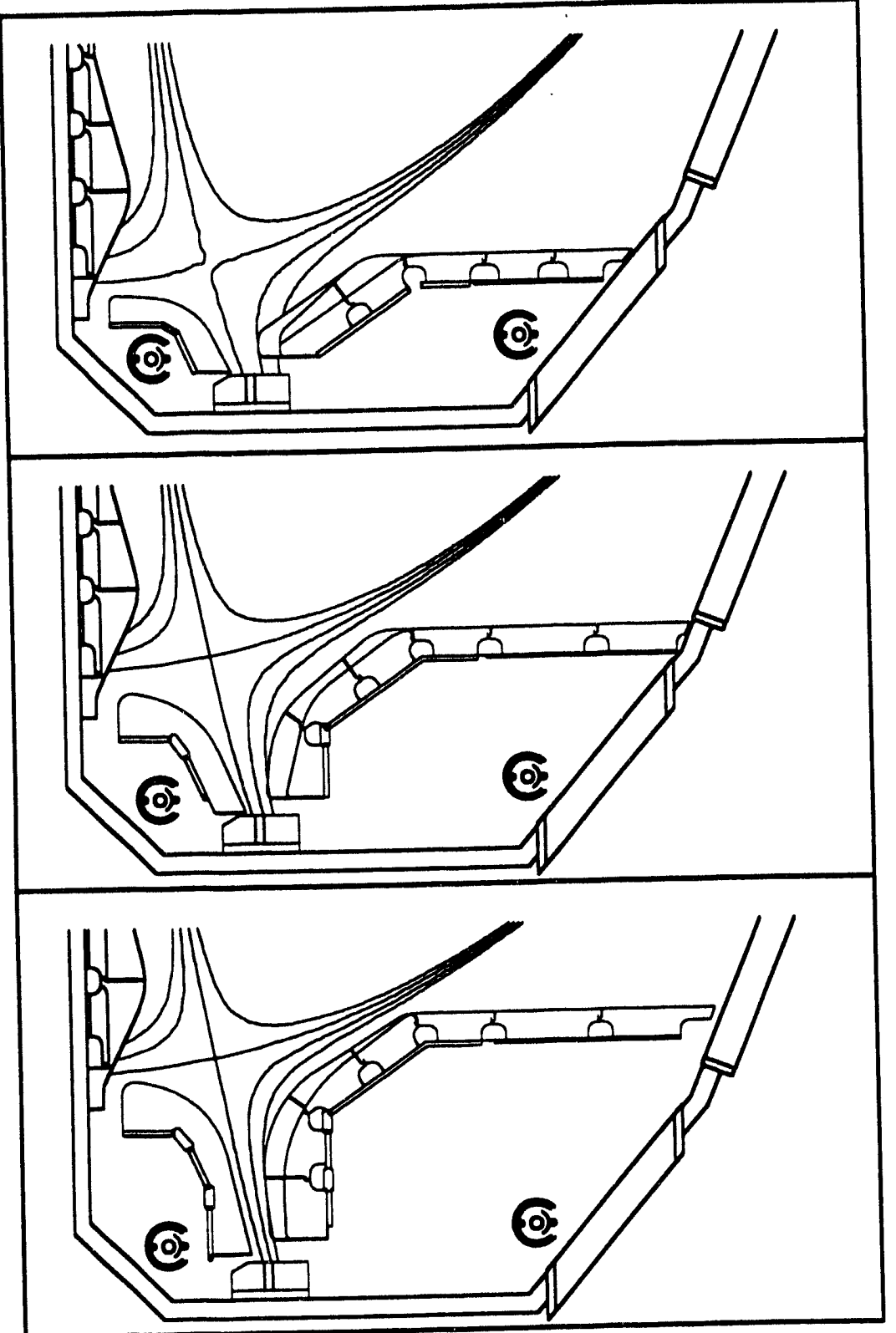

\section{$23 \mathrm{~cm}$ slot Field Line Length $=11 \mathrm{~m}$}

\section{$33 \mathrm{~cm}$ slot Field Line Length $=12.75 \mathrm{~m}$}

\section{$43 \mathrm{~cm}$ slot Field Line Length $=13.25 \mathrm{~m}$}

Fig. 11. Variations of radiative divertor geometry

mantle observed in present experiments; this implies that leakage around the divertor plasma in the existing (open) divertor may be the primary source of the core impurity influx and will be eliminated by the RD slot. Preliminary modeling of impurities with the UEDGE code is presented in Ref. 10. Detailed Monte-Carlo transport calculations of impurity transport in the RD are currently being developed (Lippmann [26]). 
A key ingredient in the experiments with the RD is the diagnosis of the divertor and SOL plasmas during operation. We will modify existing diagnosstics and add new instruments where needed. The most important quantities to measure are: the divertor heat flux, the divertor radiation, and the neutral pressure. We plan to use slightly tangential IR camera views to measure the heat flux in the slot. Currently, we are testing this technique by measuring heat flux reduction in gas puffing experiments with active pumping (the strike point is under the ring in the $\mathrm{AD}$ during pumping experiments, and the main IR camera views from above). The 48-channel bolometer array will require modification of the views of some of the specific chords, and perhaps an additional camera location. Spectroscopy of the divertor region will be expanded. The pressure gauges are very flexible and will be readily adapted to the RD. We are also engaged in conceptual design studies for a fast retractable Langmuir probe and a Thomson scattering system of electron density and temperature measurements. 


\section{PLASMA-SURFACE INTERACTION STUDIES}

Material samples are exposed to actual divertor plasma with the DiMES mechanism (Wong [12]). Samples are placed flush with the surface of the divertor armor on the floor of the DIII-D vacuum vessel, as shown in Fig. 12. When the X-point is vertically over the sample, as depicted by the MHD flux plot in solid line, the sample sits in the private flux region sheltered from direct plasma interaction. By programmed control of X-point position (Kinoshita [45]) (dashed line in figure), the outer strike point of L, H and ELMing H-mode plasmas may be positioned over the sample for studies of erosion/redeposition (E/RE) or surface durability. In this manner, a sample may be exposed to steady-state conditions of a defined plasma regime for just a portion of a single discharge or of multiple discharges. The capability to expose material samples to selected plasma conditions in the actual magnetic geometry of a tokamak divertor, including disruptions, makes DiMES a unique resource for bench marking the E/RE codes being used to predict net erosion in next-generation devices like ITER and TPX.

The conditions of the plasma-surface interaction with the DiMES sample in DIII-D are measured with an IR camera, a radial array of Langmuir probes and spectroscopic diagnostics. The IR camera (Hill [46]) gives the radial heat flux profile across the sample. The Langmuir probe array (Buchenauer [47]) measures $n_{e}(r), T_{e}(r)$ and floating potential $\mathrm{V}_{\mathrm{FL}}$. A line-filtered CCD camera (Matthews [48]) measures the two-dimensional distribution of C II light and a multichordal divertor spectrometer (Brooks [49]) monitors C III radiation. 


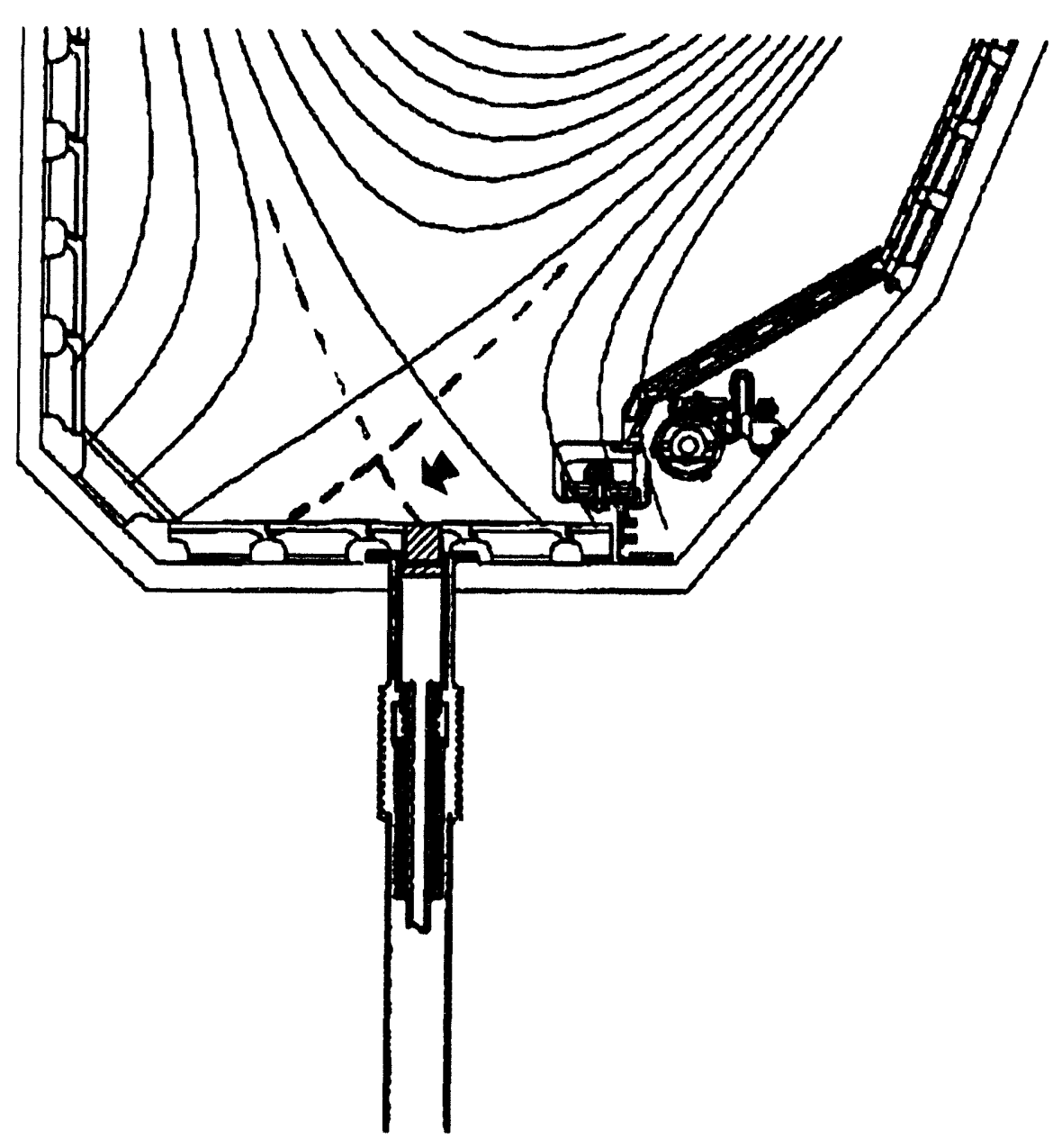

Fig. 12. DiMES sample transfer system. Sample is sheltered in the private flux region below $X$-point during the plasma startup. Divertor strikepoint is moved into the sample at the desired interval.

For one series of erosion studies (Bastasz [13]), samples of ATJ graphite were implanted with ${ }^{29} \mathrm{Si}$ at $200 \mathrm{keV}$ to form a reference marker $300 \mathrm{~nm}$ beneath the surface. One sample was also coated with a $100 \mathrm{~nm}$ thick layer of tungsten over a region $1 \mathrm{~cm}$ in diameter. The bare graphite sample was exposed to the outer strike point of ELMing $\mathrm{H}$-mode plasmas during part of 15 consecutive discharges. The instantaneous peak power deposition in these discharges was $\approx 2.5 \mathrm{MW} / \mathrm{m}^{2}$, however due to motion of the 
strikepoint the time averaged peak heat load was $0.4 \mathrm{MW} / \mathrm{m}^{2}$. The net change in the carbon surface was subsequently measured by Rutherford backscattering of a $2 \mathrm{MeV}$ electron beam from the implanted ${ }^{29} \mathrm{Si}$ layer. Figure 13 displays the net measured erosion as a function of radius. For a cumulative flux of $\sim 10^{23}$ ions $/ \mathrm{m}^{2}$, net carbon erosion of up to $60 \mathrm{~nm}$ was found, peaking near the center and inboard side of the samples. At the outboard edge of the samples net deposition of about $10 \mathrm{~nm}$ carbon occurred. The observed $4 \mathrm{~nm} / \mathrm{s}$ erosion rate of carbon indicates that plasma/surface interactions in the divertor must be carefully controlled if carbon or other low- $Z$ divertor materials are to be used in ITER.

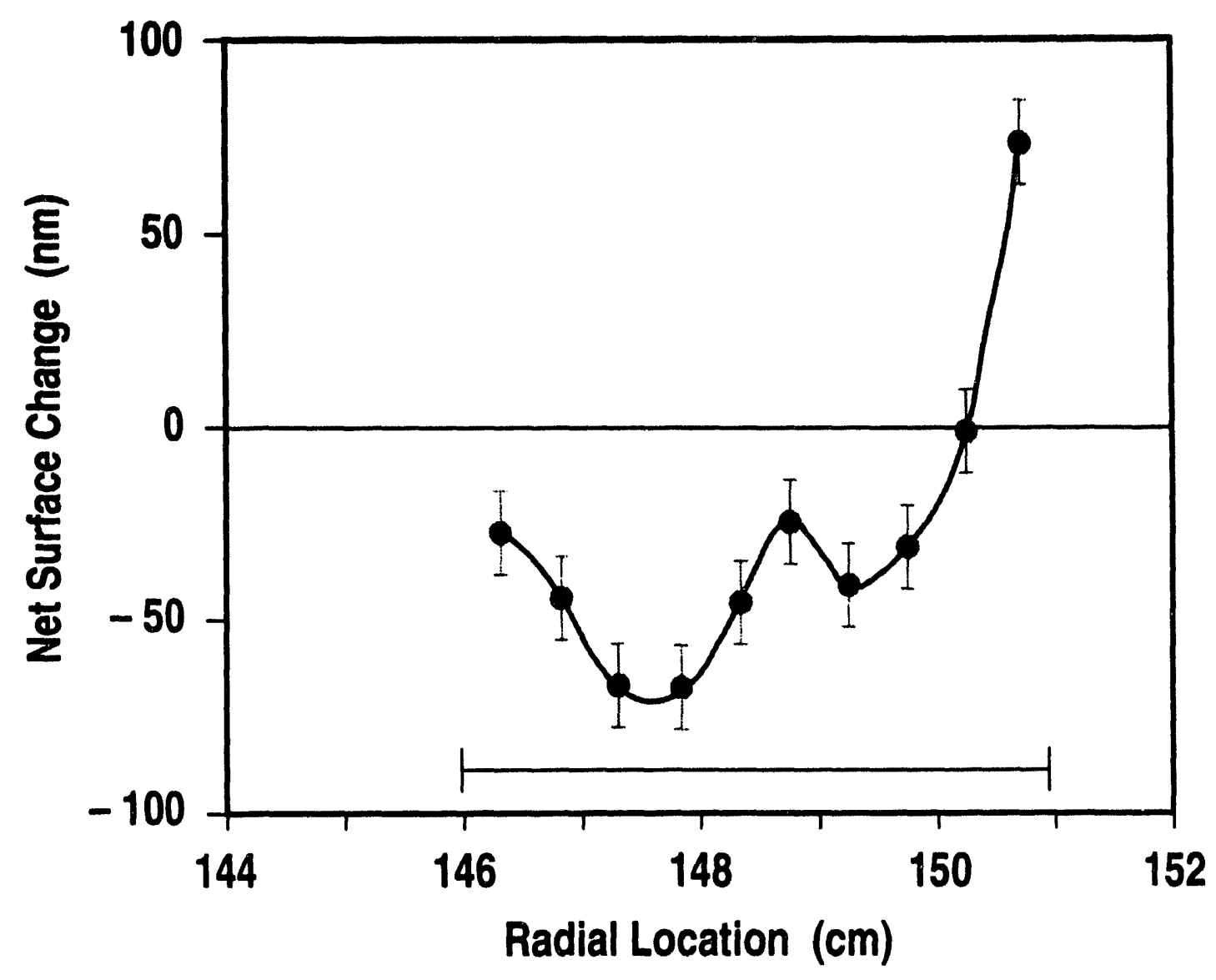

Fig. 13. Erosion of the DiMES sample. The sample was exposed to a plasma with a peak heat flux of $\approx 250 \mathrm{~W} / \mathrm{cm}^{2}$ for 15 seconds. 
A tungsten-coated sample was exposed to ELM-free $\mathrm{H}$-mode discharges (Bastasz [13]), rather than the ELMing ones used with the graphite sample. The peak power deposition was about $0.45 \mathrm{MW} / \mathrm{m}^{2}$. The time-integrated heat flux profile in these ELMfree discharges is characterized by a much faster decay on the outboard side of the peak than in the ELMing discharges. Net erosion of the tungsten spot was less than $5 \mathrm{~nm}$, the experimental limit for detectable change in the film thickness. Nevertheless, tungsten transport from the metal film onto the surrounding carbon was easily measurable and constituted an amount equivalent to three monolayer from the tungsten film. The experimental data displays an asymmetry in up- and down-field transport. As expected, the slow moving tungsten neutrals sputtered from the surface ionize and redeposit very close to their point of release.

Additional experiments performed with DiMES include durability tests of $\mathrm{B}_{4} \mathrm{C}$ layers applied to MPG-8 graphite (Buzhinskij [50]) and evaluation of in-situ boronization procedures through ex-situ analysis of deposited films. In the former experiment, a 150 micron thick boron carbide layer was exposed to 11 discharges with average heat flux of $0.4 \mathrm{MW} / \mathrm{m}^{2}$ in $\mathrm{L}$ - and $\mathrm{H}$-mode combined. The thick $\mathrm{B}_{4} \mathrm{C}$ coatings, produced by chemical vapor deposition on a high temperature substrate, demonstrated excellent durability. For monitoring film deposition during in-situ glow discharge boronization of the DIII-D vacuum vessel, a sample with an embedded silicon wafer was used to provide an clearly defined reference surface. Post-exposure Auger analysis with ion etching provided a depth profile of the film composition from which the quality of the wall conditioning procedure could be readily evaluated. In 1994, tests are planned of conversion-infiltrated films of $\mathrm{B}_{4} \mathrm{C}$ developed in Japan, of CVD films of $\mathrm{B}_{4} \mathrm{C}$ and $\mathrm{SiC}$ produced in Russia, and of beryllium surfaces. 


\section{SUMMARY AND CONCLUSIONS}

During the past year, our intensive efforts for developing an effective particle control technique came to fruition, and for the first time since the discovery of the $\mathrm{H}$-mode, density controlled $\mathrm{H}$-mode plasmas were produced. This significantly enhances the prospects of a high-confinement steady-state fusion reactor with RF current drive. We were able to independently regulate plasma current and density of $\mathrm{H}$-mode plasmas, each over a range of a factor of two. Using density regulated H-mode plasmas, a systematic scaling study of the dependence of $\mathrm{H}$-mode confinement on plasma density and current was made which shows confinement scales linearly with current and is insensitive to changes in density. It is observed that the helium density in the plasma center responds quickly to the onset of pumping and the entire helium density profile decays with a constant $\tau_{\mathrm{He}} \leq 12 \times \tau_{\mathrm{E}}$. These observations suggest that the removal of helium in these experiments is limited by the divertor exhaust efficiency and not by the rate at which helium is transported from the plasma core. We have observed that divertor pumping reduces the wall particle inventory. Although an in-vessel cryopump is not a reactor-relevant option, we conclude that in ITER the desired particle exhaust rate can be attained with a modest pumping speed.

Divertor heat load handling remains the most difficult ITER design issue. We are pursuing an intensive program of developing means of controlling the divertor heat load. In our present open divertor configuration, we have been able to reduce the divertor heat load by a factor of five by either $\mathrm{D}_{2}$ or neon injection. We have also demonstrated the efficacy of SOL flows, generated by a combination of puffing far from the divertor and divertor pumping, on reducing the impurity content of the core plasma. Using the 
experience gained from these experiments, we are designing a new Radiative Divertor for DIII-D. The results obtained during RD experiments will guide the design of future tokamaks such as TPX and ITER. The RD addresses needs for the TPX divertor: particle and power control in advanced tokamak configurations. The RD also has the basic physics ingredients of the ITER divertor, albeit in a smaller volume: radiation to lower the electron temperature and momentum loss (presumably by neutrals). An active area of research in the RD will be whether or not the shape of the radiation zone can be influenced by the divertor structure. Currently, most machines observe a small, localized zone like that measured during DIII-D gas puffing experiments. It would be advantageous to increase the volume of the radiation zone (although extrapolations of the DIII-D volume indicate that it may be sufficient even for ITER) and to be able to move it farther from the core plasma (to minimize influence on the core). 


\section{REFERENCES}

[1] T.W. Petrie, et al., J. Nucl. Mater. 196-198 (1992) 848.

[2] S.L. Allen, et al., these proceedings.

[3] G.L. Jackson, et al., Phys. Fluids B 4 (1992) 2181.

[4] G.L. Jackson, et al., these proceedings.

[5] M.A. Mahdavi, et al., J. Nucl. Mater. $176 \& 177$ (1990) 32.

[6] M.M. Menon, et al., Fusion Technol.

[7] J.P. Smith, et al., in Proc. 15th Symp. on Fusion Engineering, IEEE (Hyannis, Massachusetts, October 11-15, 1993).

[8] K.M. Schaubel, et al., in Proc. of 1993 Cryogenic Engineering Conferencde, July 12-16, 1993, Albuquerque, New Mexico.

[9] M.A. Mahdavi, et al., in Proc. 20th European Conference on Controlled Fusionand Plasma Heating, Lisbon, Portugal, 1993, (European Physical Society, Petit-Lancy, Switzerland, 1993) Vol. 17C, Part II, p. 747.

[10] D.P. Schissel, et al., submitted to Nucl. Fusion.

[11] M.R. Wade, et al., these proceedings.

[12] C.P.C. Wong, J. Nucl. Mater. 196-198 (1992) 871.

[13] R. Bastasz, et al., these proceedings.

[14] A.W. Leonard, et al., to be published in Proc. 10th Annual High Temperature Plasma Diagnostics Conference, Rochester, New York, May 8-12, 1994.

[15] D.N. Hill, et al., these proceedings; C.J. Lasnier, et al., these proceedings.

[16] T.E. Evans, et al, these proceedings.

[17] M.M. Menon, et al., submitted to J. Fusion Technol. 
[18] K.M. Schaubel, et al., in Proc. 15th Symp. on Fusion Engineering, IEEE (Hyannis, Massachusetts, October 11-15, 1993).

[19] M.A. Mahdavi, et al., in Proc. 15th Symp. on Fusion Engineering, IEEE (Hyannis, Massachusetts, October 11-15, 1993).

[20] G.L. I aughon, et all.,

[21] T. Rognlien, et al., J. Nucl. Mater. 196-198 (1992) ???

[22] B. Braams, et al., J. Nucl. Mater. 121 (1984) 75.

[23] D.B. Heifetz, et al., Plasma Wall Interactions in Controlled Fusion (Plenum, New York, 1986) p. 413.

[24] G.D. Porter, et al., PET Conference, 1993.

[25] M.E. Fenstermacher, et al., these proceedings.

[26] S.I. Lippmann, et al., these proceedings.

[27] G.L. Jackson, et al., Nucl. Fusion 20 (1990) 2305.

[28] D.L. Hillis, et al., J. Nucl. Mater. 196-198 (1992) 35.

[29] M.R. Wade, et al., in Proc. 20th European Conference on Controlled Fusion and Plasma Heating, Lisbon, Portugal, 1993, (European Physical Society, Petit-Lancy, Switzerland, 1993) Vol. 17C, Part I, p. 63.

[30] R. Maingi, et al., this conference.

[31] P.K. Mioduszewski, et al., this conference.

[32] G.L. Jackson, et al., J. Nucl. Mater. 162-164 (1989) 489.

[33] N. Ohyabu, Nucl. Fusion 9 (1979) 1491; N. Ohyabu, Kakuyogo Ken Kyu, Nucl Fusion Rsearch 46.

[34] M. Shimada, et al., Nucl. Fusion 22 (1982) 643.

[35] N. Ohyabu, Nucl. Fusion 21 (1981) 15.

[36] S.L. Allen, et al., J. Nucl. Mater. 196-198 (1992).

[37] Ph. Ghendrih, et al., these proceedings.

[38] K. Borrass, G. Janeschitz, submitted to Nucl. Fusion 
[39] M.J. Schaffer, et al, submitted to Nucl. Fusion

[40] E.A. Lazarus, et al., to be published.

[41] P. Couture, A. Boileau, R. Decoste, B. Gregory, Phys. Lett. A 163 (1992) 204.

[42] M.J. Schaffer, in Proc. 9th IAEA Workshop on Stellarators, May 10-14, 1993, Garching, Germanu.

[43] M.E. Fenstermacher, et al.,

[44] R. Campbell, et al., Bull. Am. Phys. Soc. 1993.

[45] S. Kinoshita, et al., "Independent Control of Gaps in Single-Null Divertor Discharges on the DIII-D Tokamak," General Atomics Report GA-A19584 (1989)

[46] D.N. Hill, et al., Rev. Sci. Instrum. 59 (1988) 1878.

[47] D. Buchenauer, et al., Rev. Sci. Instrum. 61 (1990) 2873.

[48] G.F. Matthews, et al., Proc. 18th EPS Conf. on Controlled Fusion and Plasma Physics, Berlin, 1991, Europhysics Conf. Abstract, Vol. 15C, Part III, p. xx.

[49] N.H. Brooks, et al., Rev. Sci. Instrum. 63, (1992) 5167.

[50] Buzhinskij, these proceedings. 


\section{ACKNOWLEDGMENT}

The divertor cryopump project is a part of the DIII-D advanced divertor program with participation of GA, LLNL, ORNL, SNL, and UCLA. The authors wish to thank Dr. T.C. Simonen for valuable suggestions. 

